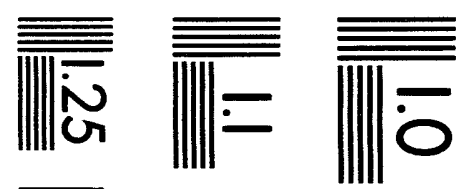

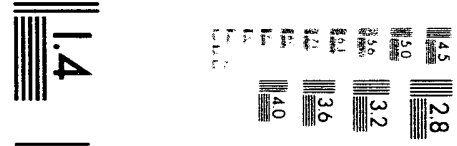

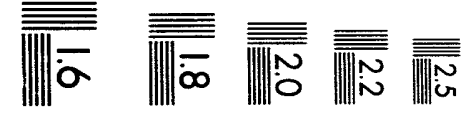



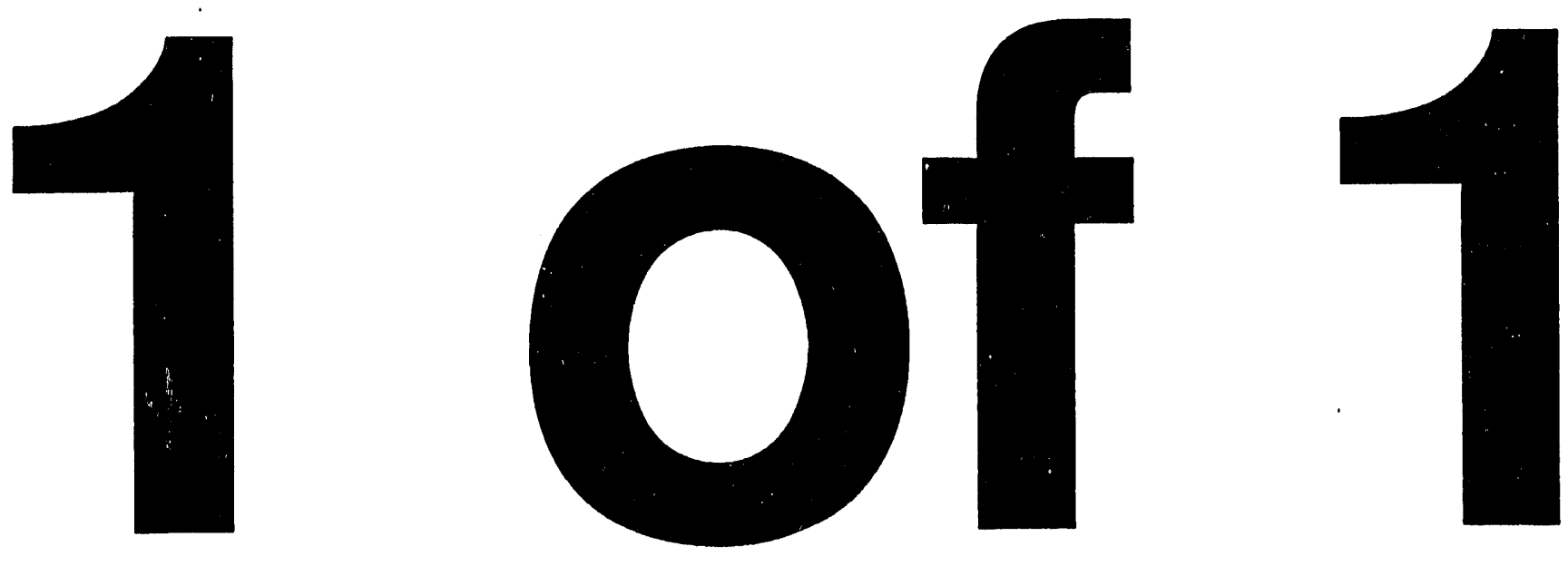


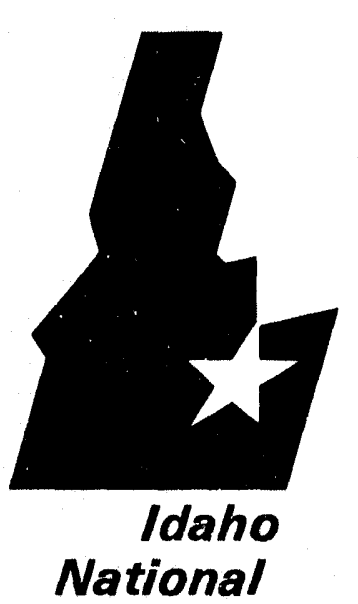

Engineering Laboratory

Managed

by the U.S.

Department

of Energy
EGG-NRE-10803

May 1993

\section{TECHNICAL REPORT}

COMPARISON OF TRAC-BF1 CALCULATIONS WITH THE LASALLE 2 INSTABILITY EVENT

Jay R. Larson

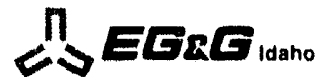

Work performed under

DOE Contract No. DE-ACO7-761D01570
Prepared for the

U.S. NUCLEAR REGULATORY COMMISSION

\section{MASTER}

MISTREUTION OF THIS DorUMER: IS Undiniren 


\section{NOTICE}

This report was prepared as an account of work sponsored by an agency of the United States Government. Neither the United Sates Government nor any agency thereof, nor any of their employees, makes any warranty, expressed or implied, or assumes any legal liability or responsibility for any third party's use, or the results of such use, of any information, apparatus, product or process disclosed in this report, or represents that its use by such third party would not infringe privately owned rights. 


\title{
COMPARISON OF TRAC-BF1 CALCULATIONS WITH THE LASALLE 2 INSTABILITY EVENT
}

JAY R. LARSON

Published May 1993

IdAHO National Engineering LabORATORY EG\&G IDAHO, INC. IDAHO FALLS, IDAHO, INC.

\author{
PREPAREd FOR THE \\ U. S. Nuclear Regulatory COMmission \\ AND FOR THE \\ U. S. Department of Energy \\ OFFICE OF ENERGY RESEARCH \\ UNDER DOE FIELD OFFICE, IDAHO \\ CONTRACT DE-AC07-76ID01570
}




\section{ABSTRACT}

In March of 1988 the LaSalle 2 BWR, while at about 85 percent power, was exposed to a loss of both recirculation pumps providing drive flow to the jet pumps. Within a few minutes the reactor power began to oscillate, resulting in an overpower scram. This report presents results of calculations performed with the TRAC-BF1 code to assess the capability of the code to calculate the observed behavior of the LaSalle plant during the event. 


\section{SUMMARY}

In March of 1988 the LaSalle 2 BWR was operating at about 85 percent of full power when an operator error resulted in a trip of the two recirculation pumps providing drive flow to the jet pumps. Additionally, a feedwater heating control system failed, resulting in a gradual decrease in feedwater temperature. Within five minutes of the pump trip, reactor power began to oscillate. After an additional two minutes the reactor scrammed on an overpower trip.

Analysis has been conducted to assess the capability of the TRAC-BFl code to calculate the observed behavior. The General Electric Co. (GE) provided an input listing describing the plant for the TRACG code. This listing was converted to the format for the TRAC-BF1 code. Included with the listing were steady-state conditions for 100 percent power, feedwater flow rate and steamline back pressure control systems, a feedwater temperature-time history, and point kinetics reactivity coefficients for the transient. The input data were provided under an agreement treating the information as proprietary and thus is not described in this report. However, this report does include a description of the model nodalization.

Initially the model was exercised at the 100 percent power, full flow condition to compare the results with the GE provided input. Several iterations were required to adjust the steam separator flow resistances to match the GE pressure distribution. Next, a steady-state calculation was performed for the pre-transient condition based on available information for the plant condition. The transient event was then simulated by tripping the recirculation pumps and initiating the reactivity feedback logic. The transient behavior was calculated with two different void reactivity coefficients, one provided by GE, and one taken from similar work accomplished by Brookhaven National Laboratory (BNL).

For the results obtained using the GE void reactivity coefficient, the calculated power oscillations occur very early during the transient in comparison with observed plant behavior and the magnitude of the power oscillation is overpredicted. For the results with the BNL void reactivity 
coefficient, the comparisons for the beginning of the power oscillation and the oscillation magnitude are better than those for the GE calculation but still deviate considerably from observed behavior. The period of the power oscillations is about 3.8 seconds for both calculations, significantly larger than the observed 2.3 seconds. Because of the better comparison obtained with the BNL void reactivity coefficient, additional results and discussion are limited to usage of the BNL void coefficient.

Calculational results are shown for a number of plant parameters. Comparisons are made with limited data for the core flow rate, feedwater flow rate, steamline flow rate, and steam dome pressure. The calculated flow rates are higher than the data and the calculated steamdome pressure is lower than the data. During the calculation the results are perturbed by several large downcomer water level oscillations that are unphysical and believed to be numerically induced. After the first set of level oscillations, a quasisteady limit cycle exists until two additional level oscillations occur. Following the last level oscillation the downcomer recirculation ratio increases slightly, thereby increasing the core inlet temperature. This causes the average power and power oscillation magnitude to diminish and the core flow rate to increase.

Conclusions are summarized as follows:

1. The TRAC-BF1 code with the LaSalle 2 model predicts the onset on instability and the development of limit cycle oscillations. However, the onset of instability occurs too early and the growth in the magnitude of the power oscillations is too large as compared to plant data.

2. The period of the oscillations calculated by TRAC-BFI is considerably longer than the measured period in the plant. This difference could be attributed to several factors, including the use of point kinetics and the lack of realistic interaction with the steam flow controller and feedwater controller. It is known that longer period oscillations result in higher power peaks. 
3. The calculated sensitivity of the point of onset and magnitude of the power oscillations to small changes in the void reactivity coefficient is dramatic. The BNL-supplied coefficient produced results closer to observed plant behavior.

4. An increased recirculation ratio is calculated after the largest power peaks occur. This increases feedwater heating in the downcomer, thereby reducing subcooling at the core inlet. This "self-correcting" behavior is plausible. 


\section{CONTENTS}

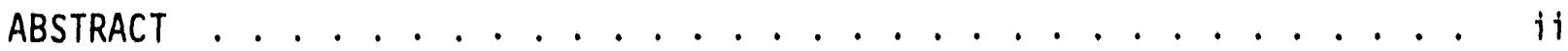

SUMMARY .......................

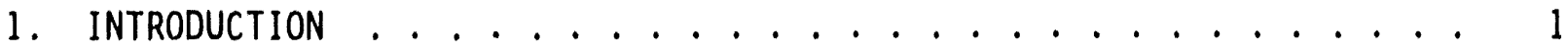

2. CODE AND MODEL DESCRIPTIONS ................. 2

2.1 Code Description . . . . . . . . . . . . . . . . 2

2.2 Model Description . . . . . . . . . . . . . . . . . 4

2.2.1 Thermal-Hydrautic Model ........... 4

2.2.2 Control System Models ............. . 8

2.3 Steady State Conditions ................ . . 9

2.4 Transient Conditions ............... 11

3. ANALYSIS RESULTS ................... 12

3.1 System Behavior. . . . . . . . . . . . . . . . . 12

3.1 .1 Power . . . . . . . . . . . . . 12

3.1.2 Jet Pump Recirculation Line flow Rate . . . . . . . . 18

3.1 .3 Core Flow Rate ................. 18

3.1 .4 Core Inlet Temperature . . . . . . . . . . . . 18

3.1 .5 Feedwater Flow Rate ................ 22

3.1 .6 Steam Flow Rate ................... 22

3.1 .7 Steam Dome Pressure . . . . . . . . . . . . . . . . . . 23

3.1.8 Downcomer Liquid Level . . . . . . . . . . . . . . . . . 27

3.2 Core Reactivity Behavior ... . . . . . . . . . . 27

3.2.1 Total Reactivity. . . . . . . . . . . 28

3.2 .2 Core Average Void Reactivity ............ 31

3.2.3 Average Fuel Temperature Reactivity ......... 31

3.2.4 Average Moderator Temperature Reactivity . . . . . . 31

3.3 Fuel Channel Behavior . . . . . . . . . . . . . . . . 32

3.3.1 Mass Flow Rates . . . . . . . . . . . . . . . . . 38

3.3.2 Single and Two-Phase Pressure Drops ......... 38

3.3.3 Channel Leakage Flow Rate . . . . . . . . . . 38

3.4 Instability .................. 42

4. CONCLUSIONS ............................ . . 44

5. REFERENCES ..................... . . . 45

TABLES

TABLE 1. PRE-TRANSIENT LASALLE 2 STEADY-STATE CONDITIONS ... . . . 9

TABLE 2. PRE-TRANSIENT LASALLE 2 CHANNEL STEADY-STATE CONDITIONS . . . . 10

TABLE 3. PRE-TRANSIENT LASALLE 2 STEAM SEPARATOR SIEADY-STATE

CONDITIONS . . . . . . . . . . . . . . . . 10

TABLE 4. LASALLE 2 TRANSIENT BOUNDARY CONDITIONS .......... 11 


\section{FIGURES}

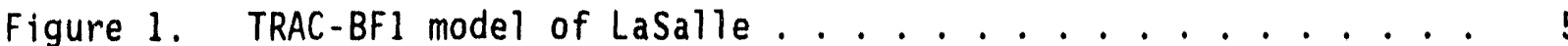

Figure 2. Comparison of TRAC-BF1 calculated power locus for two void reactivity coefficients with LaSalle plant process data and the Startup Transient Recorder (STARTREC) data . . . . . . . 14

Figure 3. TRAC-BFl calculated power with the BNL void reactivity coefficient for the LaSalle Incident. . . . . . . . . . . . . 16

Figure 4. TRAC-BFI calculated jet pump recirculation line flow rate for the LaSalle incident. . . . . . . . . . . . . . . . 17

Figure 5. TRAC-BF1 calculated flow rate to plant process data for the LaSalle incident. .. . . . . . . . . . . . . . . . 20

Figure 6. TRAC-BFl calculated core inlet coolant temperature in the center ring for the LaSalle incident. . . . . . . . . . . . . 21

Figure 7. TRAC-BFl calculated feedwater flow rate compared to plant process data for the LaSalle incident. . . . . . . . . . . 24

Figure 8. TRAC-BF1 calculated steam line flow rate compared to plant process data for the LaSalle incident. . . . . . . . . . . 25

Figure 9. TRAC-BFI calculated steam dome pressure compared to plant process data for the LaSalle incident. . . . . . . . . . . . 26

Figure 10. TRAC-BF1 calculated downcomer liquid level for the LaSalle Incident. . . . . . . . . . . . . . . . . . . . 29

Figure 11. TRAC-BFI calculated total reactivity for the LaSalle incident. . . . . . . . . . . . 30

Figure 12. TRAC-BFI calculated core average void for the LaSalle incident. . . . . . . . . . . . . . . . . . 33

Figure 13. TRAC-BFI calculated core average void reactivity for the LaSalle incident .................. 34

Figure 14. TRAC-BFl calculated average fuel temperature for the LaSalle incident. . . . . . . . . . . . . . 35

Figure 15. TRAC-BFI calculated fuel temperature reactivity for the LaSalle incident. . . . . . . . . . . . . . . . 36

Figure 16. TRAC-BFI calculated moderator temperature for the LaSalle incident. . . . . . . . . . . . . . . . . . . 37

Figure 17. TRAC-BFI calculated average moderator temperature reactivity for the LaSalle incident. . . . . . . . . . . . . . . . 39

Figure 18. TRAC-BFI calculated channel inlet and exit mass flow rates for the Lasalle incident. ........... . . . . . 4 40

Figure 19. TRAC-BFl calculated single and two phase pressure drops at channel inlet and outlet. . . . . . . . . . . . . . 41

Figure 20. TRAC-BFI calculated channel leakage flow rate for the LaSalle incident. . . . . . . . . . . . . . . . . 4 43 


\section{COMPARISON OF TRAC-BF1 CALCULATIONS WITH THE LASALLE 2 INSTABILITY EVENT}

\section{INTRODUCTION}

In March of 1988 the LaSalle 2 BWR plant was operating at about 85 percent of full polver when, during a routine test procedure, a valving error occurred. This error resulted in the trip of both recirculation pumps providing drive flow to the jet pumps. Consequently the power decreased sharply as the reactor approached natural circulation conditions. The large drop in power initially reduced the steam supply to the feedwater heaters. The feedwater heating control system then failed resulting in a gradual decrease in feedwater temperature. Within five minutes of pump trip, reactor power began to oscillate. After about seven minutes the reactor scrammed at an overpower of about 118 percent of full power.

The analysis reported here was conducted to assess the capability of the TRAC-BFl code to calculate the observed behavior. An input listing for the TRACG code, along with steady-state conditions for a 100 percent power calculation and feedwater and steamline back pressure control systems, was obtained from the General Electric Company. Point kinetic reactivity coefficients and feedwater temperature time history data for the transient were also obtained. The input for the plant was converted to the TRAC-BFI format and calculations were performed. The model input data were provided under an agreement treating the information as proprietary. Therefore detailed mode? input data are not presented in this report.

The following report sections describe the TRAC-BF 1 code, the model of the plant, the calculation of plant parameters with comparisons with limited plant data where available, a brief discussion of problems encountered, and conclusions. 


\section{CODE AND MODEL DESCRIPTIONS}

The following sections describe the TRAC. BF1 computer code and the model of the LaSalle reactor representing the $p l a n t$, the pre-transient steady state conditions, and the transient boundary conditions.

\subsection{Code Description}

The TRAC-BFI computer code' provides a best-estimate analysis capability for analyzing a full range of postulated accidents in existing bolling water reactors (BWRs). This code evolved from the TRAC computer code ${ }^{2}$ that was developed at Los Alamos National Laboratory for the analysis of loss-ofcoolant (LOCA) accidents in pressurized water reactors. The code development program at the Idaho National Engineering Laboratory began in October 1979; $T R A C-B D 1^{3}$ was the first publicly released version of the code. The mission of TRAC-BDI was to provide a best estimate capability for analysis of design basis LOCAs in BWRs. The code provided the capability for simulating the blowdown, heatup, reflood, and refill phases of design basis LOCAs. The second publicly released version of the code, TRAC-BDI/MODI ${ }^{4}$ had an expanded mission that included not only large and small break LOCAs, but also operational transients and anticipated transients without scram for which point reactor kinetics was applicable. Models added in TRAC-BD1/MOD1 included balance of plant models (such as turbine, feedwater heaters, and condenser), a simple lumped-parameter containment model, reactivity feedback model for use with point reactor kinetics, a soluble boron transport model, a noncondensable gas transport model, a two-phase level tracking model, control systems models, and generalized component-to-component heat and mass transfer models.

The third publicly released code version was TRAC-BF $1^{\prime}$ that provided additional models and model refinements beyond TRAC-BDI/MOD1. These model extensions included a Courant-violating numerical solution scheme for onedimensional components, implicit steam separator/dryer models, implicit turbine models, an improved interfacial package, a condensation model for stratified vertical flow, and a one-dimensional neutron kinetics model allowing simulation of space-dependent variations of power in ATWS-type transients. 
TRAC-BF1 includes a full, nonhomogeneous, nonequilibrium, two-fluid, thermal-hydraulic model of two-phase flow in all portions of a BWR system. A three-dimensional (axial, radial, and azimuthal) thermal-hydraulic modeling capability is provided for the reactor vessel. The remainder of a BWR system is modeled with one-dimensional representations.

The basic field equations include conservation relations for mass, momentum, and energy for the two fluid phases. A flow regime map is incorporated to provide needed interphase and phase-boundary relationships. Fluid-energy and fluid-mass-conservation field equation closure relations are provided for interfacial heat transfer, wall heat transfer, and radiation heat transfer. Fluid-momentum conservation field equation closure relations are provided for interfacial drag, wall friction, and level tracking.

The flow regime map was developed for vertical pipe flow. The local flow regime is classified according to void fraction and mass flux. The map is used to determine the flow regime that exists in a computational cell, independent of the fluid cell orientation. Once the regime is determined, its constitutive relations are used to determine the interfacial area and heat transfer coefficients for the cell. The flow regime map includes basic regions representing bubbly, bubbly-slug, and annular mist flow. Between these regions, mathematical interpolations are used to smooth transitions from one region to another.

The wall-to-fluid heat transfer coefficients are obtained from a generalized boiling curve. Models calculate heat transfer for condensation, single phase flow, nucleate boiling, transition boiling, and film boiling. The critical heat flux is also computed based on a correlation.

Heat structure process models are included for heat conduction in cylindrical and rectangular geometries, metal-water reaction, and core power (including the aforementioned one-dimensional reactor kinetics).

Flow process models are included in TRAC-BFI for pressure drop due to area change, critical flow, and countercurrent flow limiting. Special component models are provided for centrifugal pumps, jet pumps, steam/water separators and dryers, and turbines. 
TRAC-BFl provides for detailed modeling of a BWR fuel bundle, including a radiation model for heat transfer between multiple fuel rod groups, liquid, and vapor phases, and the fuel channel wall with quench front tracking on all fuel rod surfaces and falling film quench fronts.

\subsection{Model Description}

This section summarizes the computational model used with TRAC-BF1. The subsections describe the thermal-hydraulic model, the control systems, the initial steady-state conditions, and the boundary conditions applied during the transient calculations. The model was obtained from the General Electric Co. ${ }^{5}$ in the form of a diskette listing input for the GE code TRACG. The model provided was not identical to the one used by GE for similar analyses but was stated to yield similar results. The transmittal from GE included steadystate conditions for 100 percent power. The model consists of 301 cells, 22 components and 37 junctions. The listing was converted to the TRAC-BFl format and calculations performed. A few modifications were made as described below.

\subsubsection{Thermal-Hydraulic Model}

This subsection describes the modeling of the vessel and one dimensional components. The model nodalization is illustrated in Figure 1. 


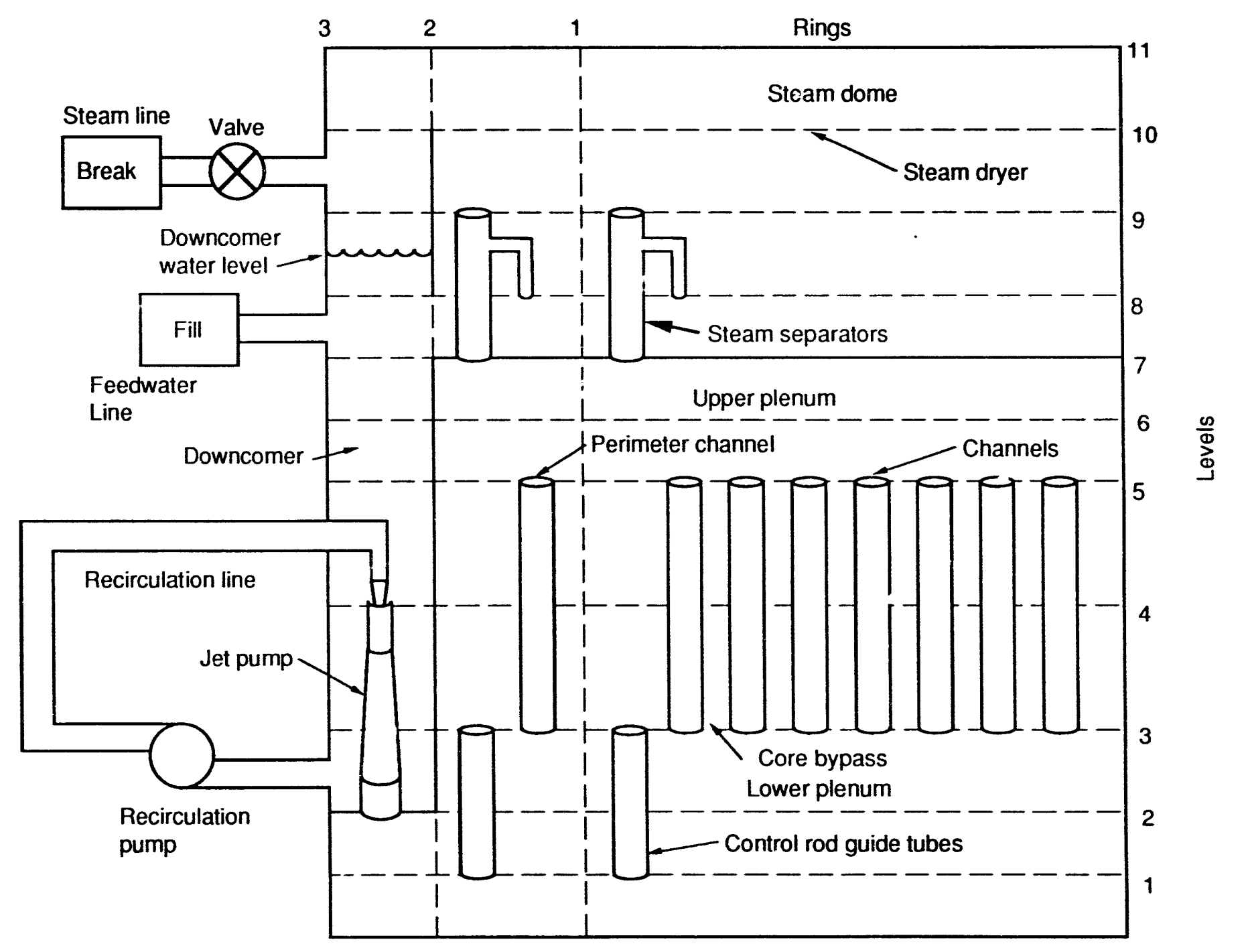

Figure 1. TRAC-BF1 model of LaSalle. 
The vessel model consists of 11 axial levels and 3 radial rings. The exterior ring represents the downcomer. The second ring represents the location of the peripheral fuel bundles and the center ring represents the remaining fuel bundles. The fuel bundles in the periphery have significantly lower power and different hydraulic conditions than the fuel bundles in the center. The inner rings al so contain the appropriate lumped number of control rod guide tubes and steam separators, and the appropriate steam dryer flow area. The levels primarily correspond to the entrance/exit elevation of the one dimensional components. Additional levels in the upper plenum and steam separator region permit vertical phase separation.

The celi flow areas, flow resistances, and volumes represent the appropriate vessel design and hydraulic characteristics. Heat structures are included representing the double sided exterior vessel wall and downcomer. Lumped masses represent the support structure, steam dryers, and other miscellaneous structure.

The level tracking model was deactivated in level 9 where the normal operating water level occurs. This change eliminated considerable instability in the water level behavior and permitted the transient calculation to proceed without continuous manometric oscillation in the downcomer/internal region.

The control rod guide tubes flow path and structure are modeled from the location of a lower leak entrance in the lower plenum to the core entrance. The flow path and structure penetrating the vessel bottom, which provides a small cooling flow, are not modeled. The tubes are lumped into two pipe components. One pipe represents 17 tubes in the second ring and one pipe represents the 146 tubes in the interior ring. The pipes are divided into 6 equally spaced cells.

The core fuel rod bundles are lumped into eight channel components, one of which represents the bundles in the core periphery. Each channel consists of two rod groups, 62 powered fuel rods and 2 unpowered fuel rods representing water rods. The radial power distribution is flat within the individual fuel rods and is flat from rod to rod within the channels. All power is generated within the fuel. The channels have 27 axial levels, two at the entrance region, 24 equally spaced levels in the active fuel region, and one 
representing the exit region. The channel to bypass leak path is located in the second cell from tha entrance. The axial power distributions are described later in the steady-state section. The channel structure is modeled for heat transfer.

The steam separators are lumped into two components. The component in the second ring which contains the peripheral channels represents 72 separators and the component in the c nter ring represents 153 separators. Three equally spaced cells represent the standpipe portion of the separator. One cell represents the location of the separation process with two cells carrying the vapor rich mixture upward to the region below the steam dryers and one cell returns the liquid rich mixture to the source of water recirculated to the downcomer. The return exit is artificially placed below the top of level 8. The separator structure is modeled for heat transfer. Preliminary results indicated that the code mechanistic separator option would not function properly. Thus, the simple separator option was selected with the liquid carryover and vapor carryunder specified as constants. The values specified were derived from the initial steady-state conditions for the $G E$ model at 100 percent power. Flow resistance was added to the standpipe section to obtain a full power pressure distribution through the separator approximately equal to that shown in the GE model.

The two recirculation pumps are lumped into one pump component. The model of the Semiscale pump was included with the GE model input description. The Semiscale pump characteristics were replaced by those describing a LaSalle pump from a Commonwealth Edison LaSalle Model Notebook developed for RETRAN input. The Commonwealth Edison Notebook ${ }^{6}$ is also proprietary. A heat transfer structure is included with no external heat transfer permitted. The pump suction and discharge recirculation lines are each lumped into equivalent pipe components. Heat transfer structures are included with no external heat transfer permitted.

The 20 jet pumps are lumped into one equivalent jet pump component including a heat transfer structure. 
The feedwater lines are lumped into one equivalent pipe component without a heat transfer structure.

The steam lines are lumped into one equivalent pipe without a heat transfer structure. The steam line includes a valve that was not activated during the calculations.

\subsubsection{Control System Models}

Two control systems are included with the model. They are for the feedwater flow rate and the steamline back pressure. The controllers approximate actual plant behavior. The feedwater controller functions by comparing the downcomer water level with a set point value and the steam flow rate with the feedwater flow rate. The water level error and flow rate difference are manipulated, combined, and further processed. The vessel steam dome pressure provides a final input to the determination of the flow rate. The inclusion of steam dome pressure as an input to the controller does not conform to the design of the actual plant controller. Rather, it is included to account for the fact that feedwater flow is affected by the pressure drop between the feedwater pumps and the reactor vessel, which is not explicitly modeled.

The back pressure controller compares the current power with the full power value, manipulates the ratio and determines the pressure value applied at the steam line break component.

The pressure control model was provided with an earlier supplied TRACG plant model that was set up for natural circulation conditions existing just prior to the onset of the power instability. The natural circulation plant model did not have as long a steam line or a valve as provided later with the full power plant model. Consequently to adjust for the additional steam line pressure loss in the full power model, a constant in the control system logic was decreased slightly from the original value provided. 


\subsection{Steady State Conditions}

The plant model described was initialized at full power, full flow conditions. This served to check out the model and provide a means for determining flow resistance values for the separators that were subsequently kept constant. To simulate the pre-transient, steady-state conditions, appropriate values for the power, core flow rate and feed water temperature were selected. The recirculation pump speed was adjusted to obtain the desired average core flow rate. All other conditions were determined by the model. The pre-transient steady-state power and core flow were based on an EPRI evaluation of the LaSalle event. The feedwater temperature was supplied by GE. The nominal initial conditions are shown in Tables 1,2 , and 3.

\section{IABLE 1. PRE-TRANSIENT LASALLE 2 STEADY-STATE CONDITIONS}

\begin{tabular}{ll}
\multicolumn{1}{c}{ Parameter } & Value \\
\cline { 2 - 2 } Reactor power (Mwt) & 2801.3 \\
Core flow rate (kg/s) & 10220 \\
Core inlet temperature (K) & 548.0 \\
Core inlet subcooling (K) & 11.1 \\
Core average void fraction (\%) & 44.9 \\
Core average fuel temperature (K) & 788.8 \\
Feedwater flow rate (kg/s) & 1480.0 \\
Feedwater temferature (K) & 478.9 \\
Drive line level flow rate (kg/s) & 2798 \\
Pump speed (rad/s) & 111.0 \\
Vessel dome steam pressure (MPa) & 6.87 \\
Vessel bottom to top pressure difference (MPa) & 0.19 \\
Core axial peak/average power & 1.30 \\
Downcomer to interior water & \\
level difference (m) & 1.0 \\
Recirculation ratio & 5.8
\end{tabular}


IABLE 2. PRE-TRANSIENT LASALLE ? CHANNEL STEADY-STATE CONDITIONS

\begin{tabular}{|c|c|c|c|c|c|c|c|c|}
\hline Parameter & Perimeter & & & Center & Ring & & & \\
\hline Bund los ronreconted & 92 & 121 & 68 & 108 & 100 & 01 & 88 & 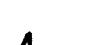 \\
\hline Inlet flow rate $(\mathrm{kg} / \mathrm{s})$ & 637 & 1730 & 2470 & 1480 & 1350 & 1110 & 1070 & 48 \\
\hline Power (Mw) & 114 & 464 & 460 & 435 & 424 & 428 & 454 & 21 \\
\hline $\begin{array}{l}\text { Maximum centerline } \\
\text { fuel temperature (K) }\end{array}$ & 709 & 1146 & 915 & 1252 & 1347 & 1644 & 1630 & 1609 \\
\hline
\end{tabular}

TABLE 3. PRE-TRANSIENT LASALLE 2 STEAM SEPARATOR STEADY-STATE CONDITIONS

$\begin{array}{lll}\quad \text { Parameter } & \text { Perimeter Ring } & \text { Center Ring } \\ \text { Separators represented } & 72 & 153 \\ \text { Inlet flow rate }(\mathrm{kg} / \mathrm{s}) & 3020 & 7220 \\ \text { Steam exit flow rate }(\mathrm{kg} / \mathrm{s}) & 510 & 1060 \\ \text { Steam exit void fraction } & 0.996 & 0.996 \\ \text { Liquid return flow rate }(\mathrm{kg} / \mathrm{s}) & 2510 & 6150 \\ \text { Liquid return void fraction } & 0.085 & 0.084\end{array}$




\subsection{Transient Conditions}

The transient calculation was initiated by tripping the plant model recirculation pump and initiating the reactivity feedback logic. Table 4 describes the boundary conditions applied. The feedwater temperature was based on data provided by GE' to 7 minutes and from Brookhaven National Laboratory (BNL) reports to 9 minutes. The calculation was concluded at 9 minutes.

To reduce the magnitude of feedwater flow oscillations the dome pressure input to the feedwater control system was fixed constant prior to the onset of the power instability. The calculation was then restarted. Likewise to reduce the effect of steam line pressure oscillation on the system flow rate oscillations, the steam line back pressure was fixed constant at the same time.

Point kinetics reactivity coefficients were used. The Doppler coefficient considered only fuel temperature effects. It was provided in the GE transmittal. Two void reactivity coefficients were alternately applied. The first came with the GE transmittal and the second was taken from BNL work. The moderator temperature coefficient was the code default value. The spacial distribution of core power on the reactivity feedback was accounted for by simple volume weighting.

\section{IABLE 4. LASALLE ? TRANSIENT BOUNDARY CONDIUIONS}

\section{Parameter Value}

Reactivity trip (s) $\quad 0.0$

Recirculation pump trip ( $s$ ) 0.0

Feedwater temperature (K) Table from plant data

Feedwater flow rate $(\mathrm{kg} / \mathrm{s}) \quad$ Control system, at 100 seconds the dome pressure input was fixed at current value

Steaml ine backpressure (MPa) Control system, at 100 seconds the pressure was fixed constant at current value 


\section{ANALYSIS RESULTS}

Code calculations and analys is are shown for the behavior of the primary system, the core reactivity, and the channel hydraulics. Comparisons with data are provided where available.

\subsection{SYSTEM BEhAVIOR}

The following section provides code results for a number of the primary system parameters. Some comparisons are made with plant data.

\subsubsection{Power}

The reactor power drives the system thermal-hydraulic response but the detalls of the response in turn shape the power behavior. Figure 2 compares code calculations of the normalized power minimum and maximum locus for two different void reactivity coefficients (GE and BNL) with 1 imited data from two plant measurement systems. The plant process data system samples data every minute after appropriate filtering and thus gives only average nominal values. The Startup Transient Recorder (STARTREC) provides data for a few parameters for a short duration. The locus of the STARTREC power measurement is also shown. The STARTREC system was initiated during the transient but was programmed to run only for one minute. The reactor scrammed at approximately $420 \mathrm{~s}$ at a power level of 118 percent. The STARTREC system terminated data collection a few seconds prior to reactor scram. The accuracy of the data from the systems is unknown.

The calculations indicate the power drops sharply following the pump trip and reaches a new quasi-steady state value. Then the power increases slightly until a two phase flow oscillation in the fuel channels couples with a reactivity feedback causing a core wide power/flow oscillation. The channel and reactivity behavior are discussed later. For the calculation with the GE void reactivity coefficient the power oscillation occurs at about 2 minutes, which is about 2 minutes earlier than observed by operators during the plant transient. Also for the calculation with the GE void reactivity coefficient the magnitude of the oscillation far exceeds the messured values. During the 
large power oscillations of both calculations an instability occurs that causes the recirculation flow into the downcomer to temporarily reverse and then carry additional saturated liquid into the downcomer, which increases the core inlet temperature. The increase in core inlet temperature reduces the magnitude of the power oscillation. The power then appears to be converging to a new quasi-steady value. 


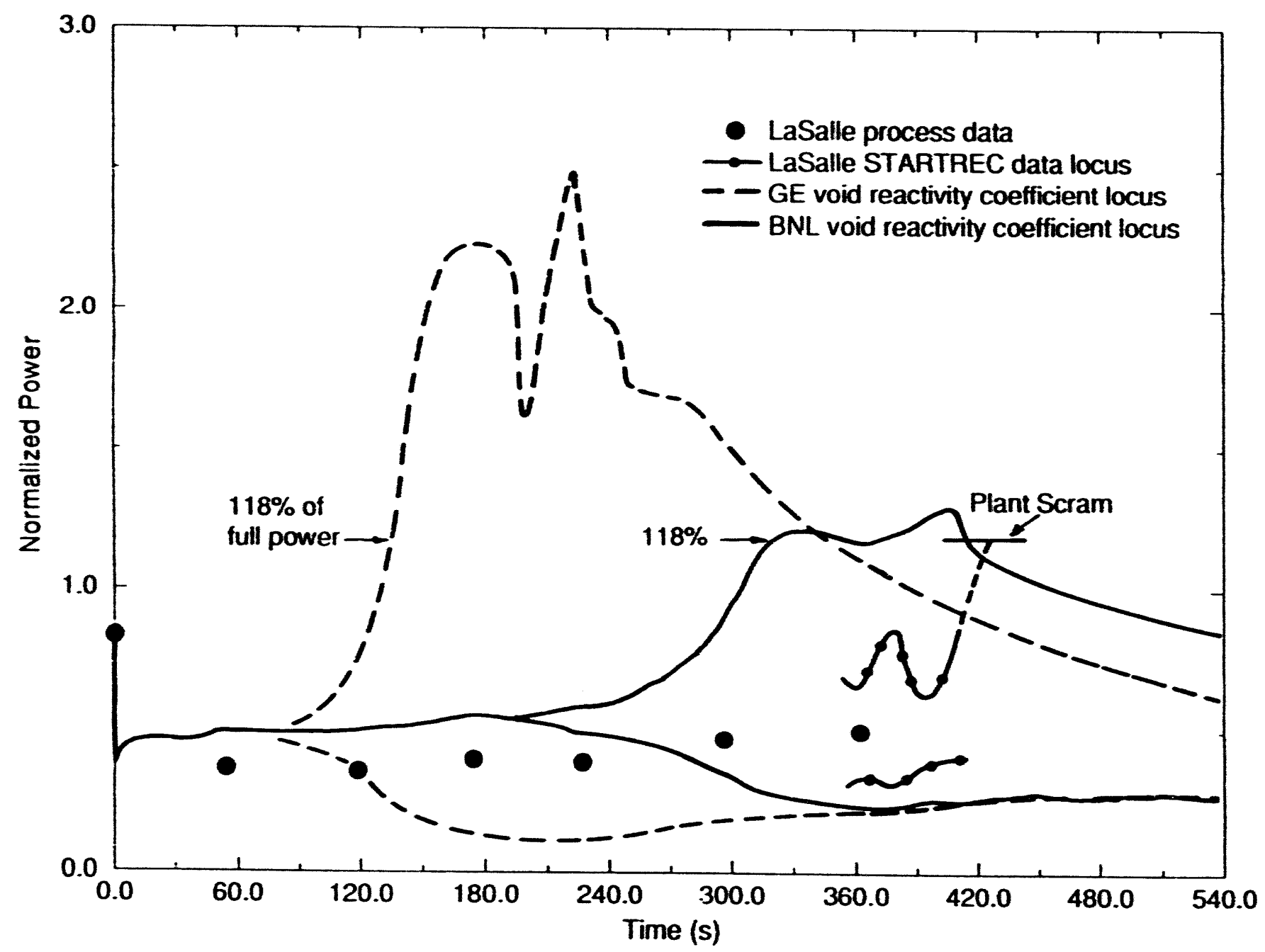

Figure 2. Comparison of TRAC-BF1 calculated power locus for two void reactivity coefficients with LaSalle plant process data and the Startup Transient Recorder (STARTREC) data. 
The large difference in power behavtor shown for the two calculations is caused by only a few percent difference in the magnitude of the void reactivity coefficients, with the BNL value teing smaller. General Electric has noted that calculations using point kinetics yield power oscillation amplitudes that are too large compared with results using three-dimensional kinetics when a sufficient number of fuel channels are used to describe the core (eight or larger). The period of the power oscillations calculated is about 3.8 seconds, significantiy longer than the 2.3 seconds observed. The phenomena occurring during the calculation with the GE vold reactivity coefficient are similar to those occurring in the calculation with the BNL vold reactivity coefficient and therefore only the latter is discussed in more detall below.

Figure 3 presents the power-time history for the calculation with the BNL vold reactivity coefficient. Near 260 seconds ( 4.3 minutes) the magnitude of the oscillation approximates that which was first observed during the $p l a n t$ transient at about 4 minutes. However, as time progresses, the calculated power significantly exceeds that shown by the plant data. The calculated oscillation grows quickly and exceeds the 118 percent value that caused the plant to scram. Shortly thereafter, at about 320 s, the calculated system behavior is perturbed by large downcomer oscillations. These are described later. A quasi-steady 1 imit cycle with near constant average power then exists until another set of downcomer oscillations occurs. The first oscillations cause slightly increased core flow, which increases the peak power values for several cycles. Between the later downcomer oscillation pair the power peaks for four cycles. Following the second oscillations the downcomer recirculation/feedwater flow rate ratio changes, increasing slightly as the calculation proceeds. This increasing ratio tends to increase the core inlet temperature and consequently reduce the peak and average power. Also the core flow rate increases slightly. It is anticipated that had the calculation continued the system would have reached a new quasi-steady natural circulation condition. 


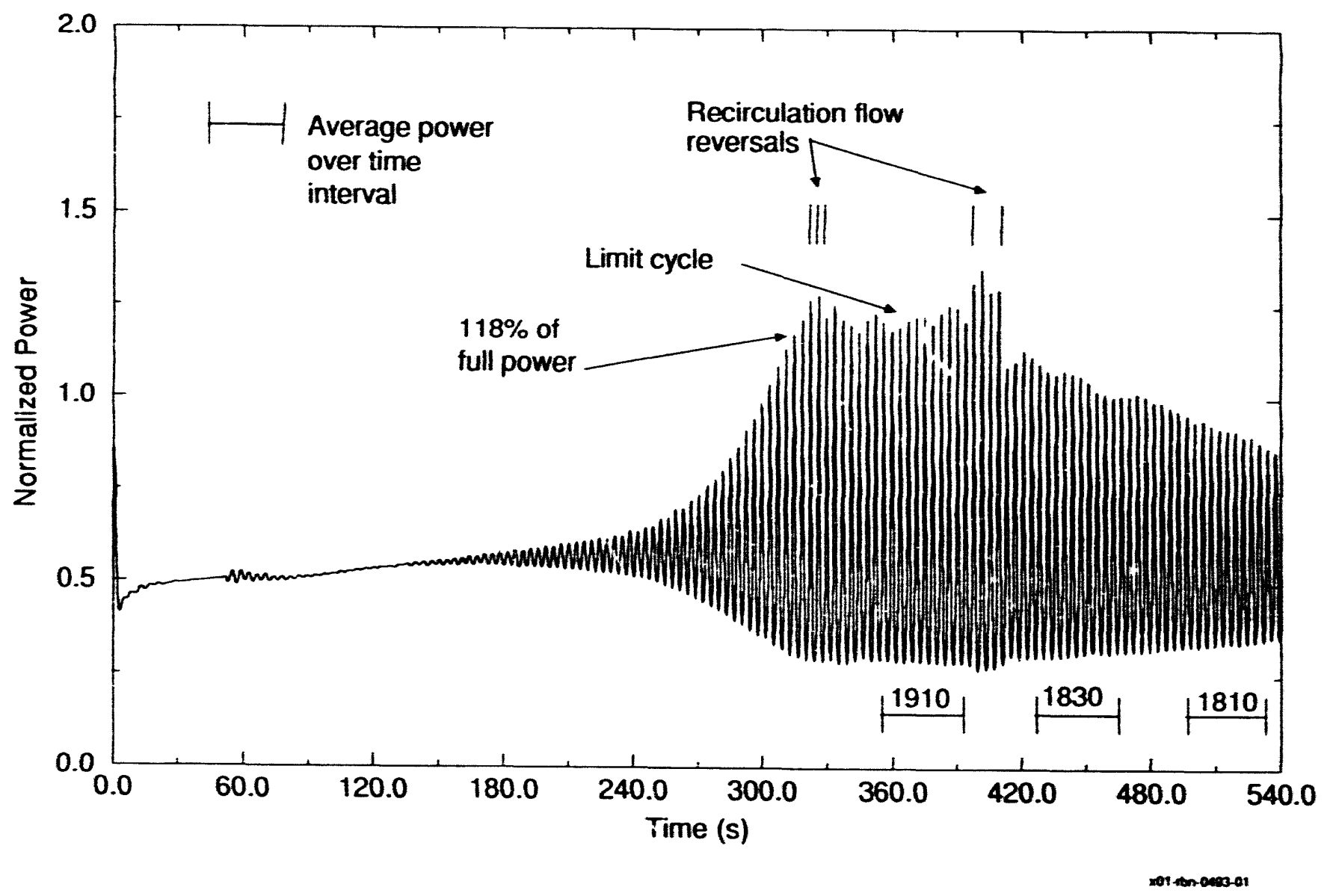

Figure 3. TRAC-BF1 calculated power with the BNL void reactivity coefficient for the LaSalle incident. 


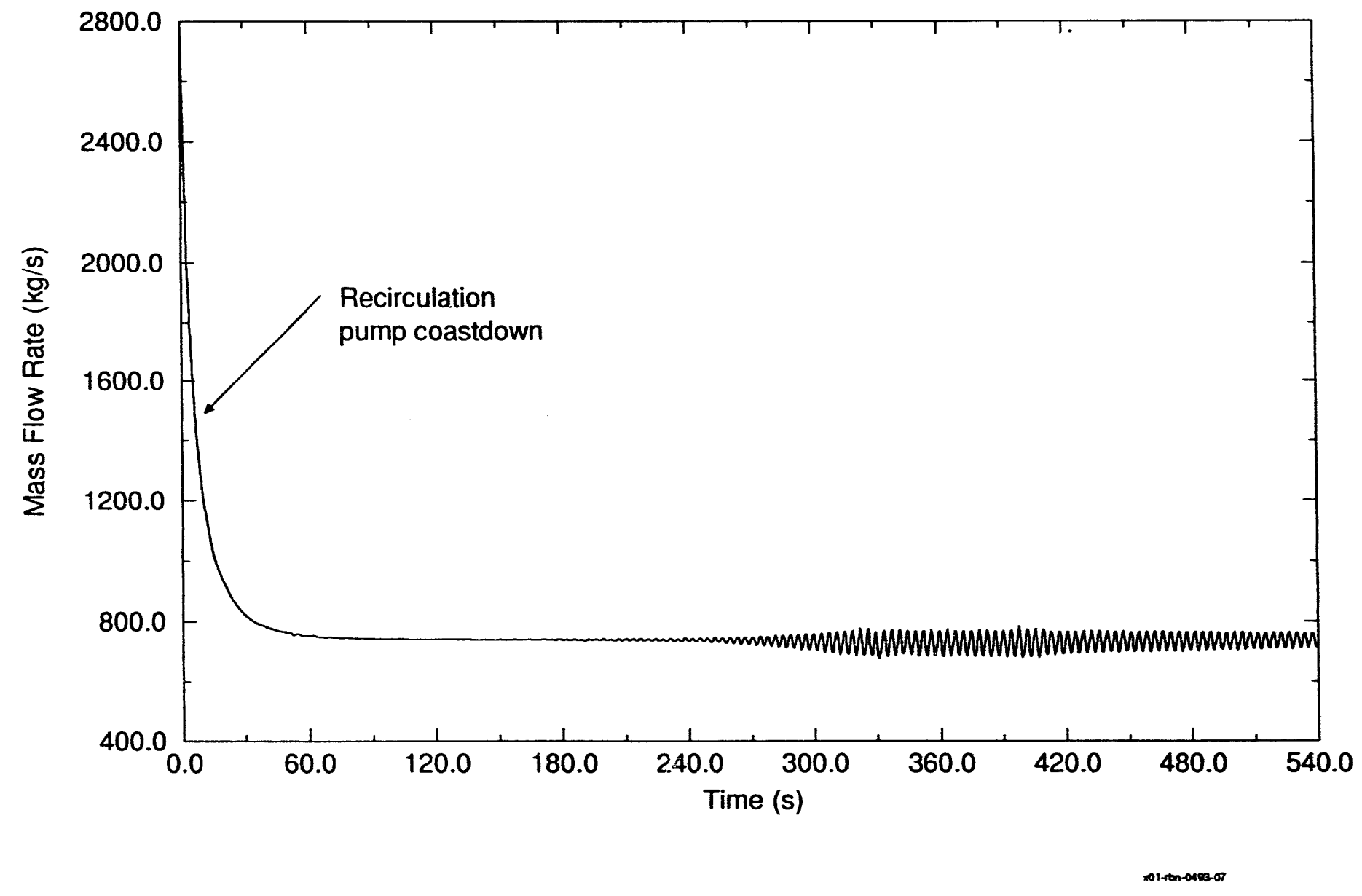

Figure 4. TRAC-BF1 calculated jet pump recirculation line flow rate for the LaSalle incident. 


\subsubsection{Jet Pump Recirculation Line Flow Rate}

Figure 4 shows the flow rate in the recirculation line furnishing drive flow to the jet pump. The flow rate quickly decreases with the trip and coast down of the recirculation pumps. The flow rate stabilizes to a non-zero value as the natural circulation flow through the jet pump to the core results in a local pressure decrease in the jet pump throat. Thus a pressure gradient exists across the recirculation line maintaining positive flow.

\subsubsection{Core Flow Rate}

Figure 5 shows the comparison of the calculated total core flow rate with plant process data. This total flow includes the channel inlet flow and the bypass flow alongside the channels. The location of the flow rate shown is at the jet pump exit. The flow rate decreases sharply with the recirculation pump trip and reaches a near constant value for several minutes prior to oscillation.

The power and flow oscillate at the same frequency but the flow rate leads the power by several tenths of a second. Between the second pair of downcomer oscillations the core flow oscillates with a larger amplitude for 4 cycles corresponding to the 4 power cycles with larger peaks shown in Figure 3. After the last downcomer oscillations, the amplitude of the core flow oscillations decrease and the average core flow rate increases. The magnitude of the core flow oscillations calculated is several times larger than observed in the STARTREC data. The magnitude of the calculated flow rate exceeds that shown for the plant process data by about 6 percent.

\subsubsection{Core Inlet Temperature}

Figure 6 shows the calculated core inlet coolant temperature in the center ring of the model. This ring furnishes coolant to all channels except the one representing the core periphery fuel bundles. The feedwater temperature declines rapidly after the transient initiation as the feedwater heaters cannot maintain the pre-transient condition. As the inlet temperature reaches a near steady value the oscillation in the power grows rapidly. The recirculation flow to the downcomer from the separators reverses which results 
in additional saturated liquid being carried into the downcomer causing a small temperature rise at the core inlet. Slightly later, an additional quantity of feedwater is injected in response to the downcomer water level drop. This additional feedwater turns over the inlet temperature rise. During the second recirculation reversal, not as much additional saturated liquid is carried into the downcomer resulting in a smaller core inlet temperature increase. Less additional feedwater injection enters the downcomer also resulting in a leveling of the inlet temperature and not a drop as seen previously. 


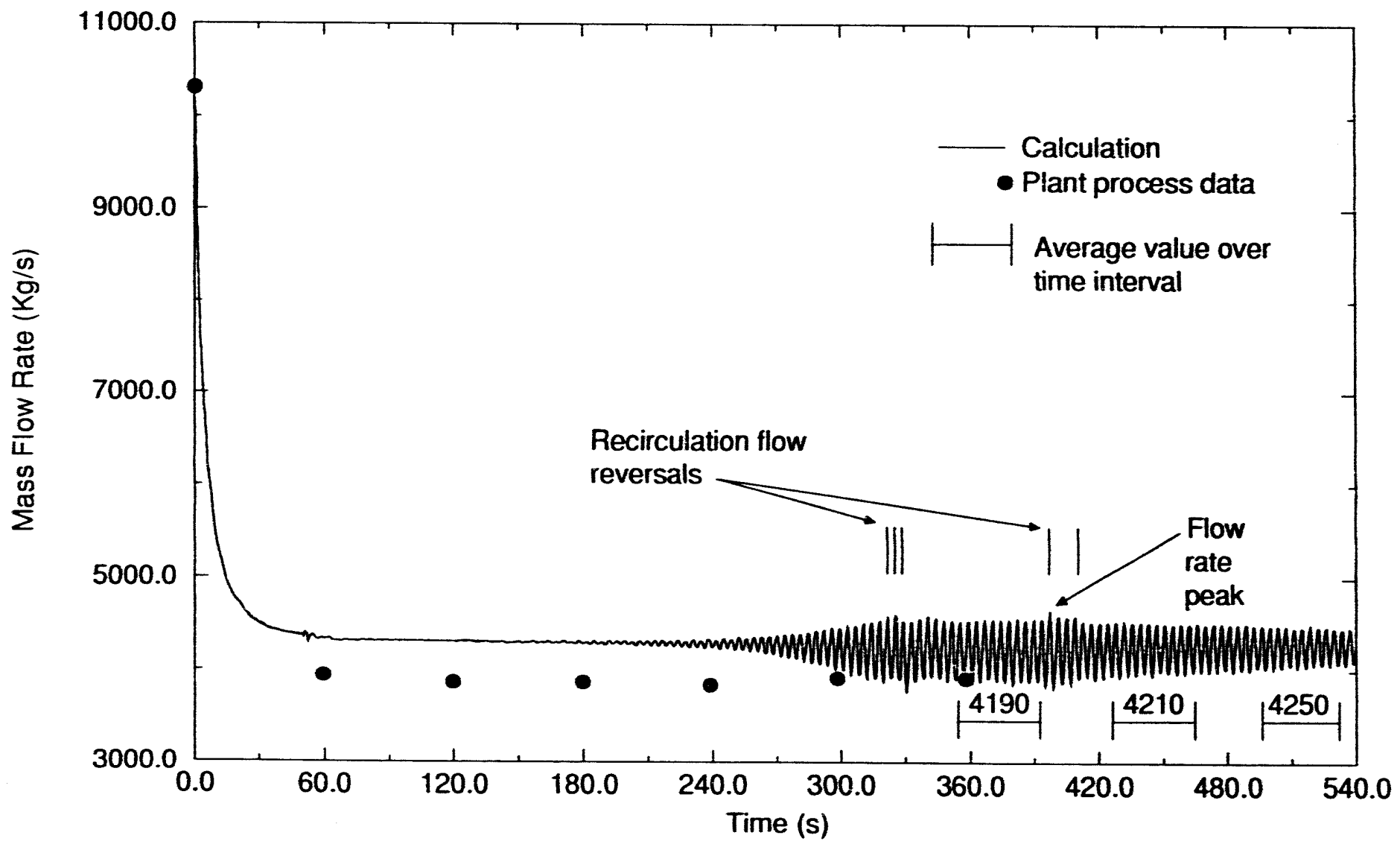

Figure 5. TRAC-BF1 calculated core flow rate compared to plant process data for the LaSalle incident. 


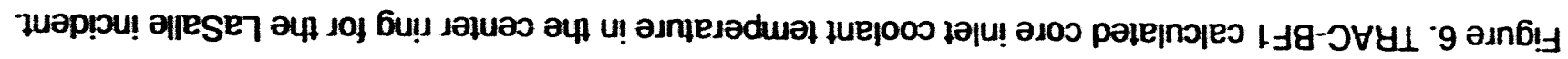
nomontson

(s) วu!1

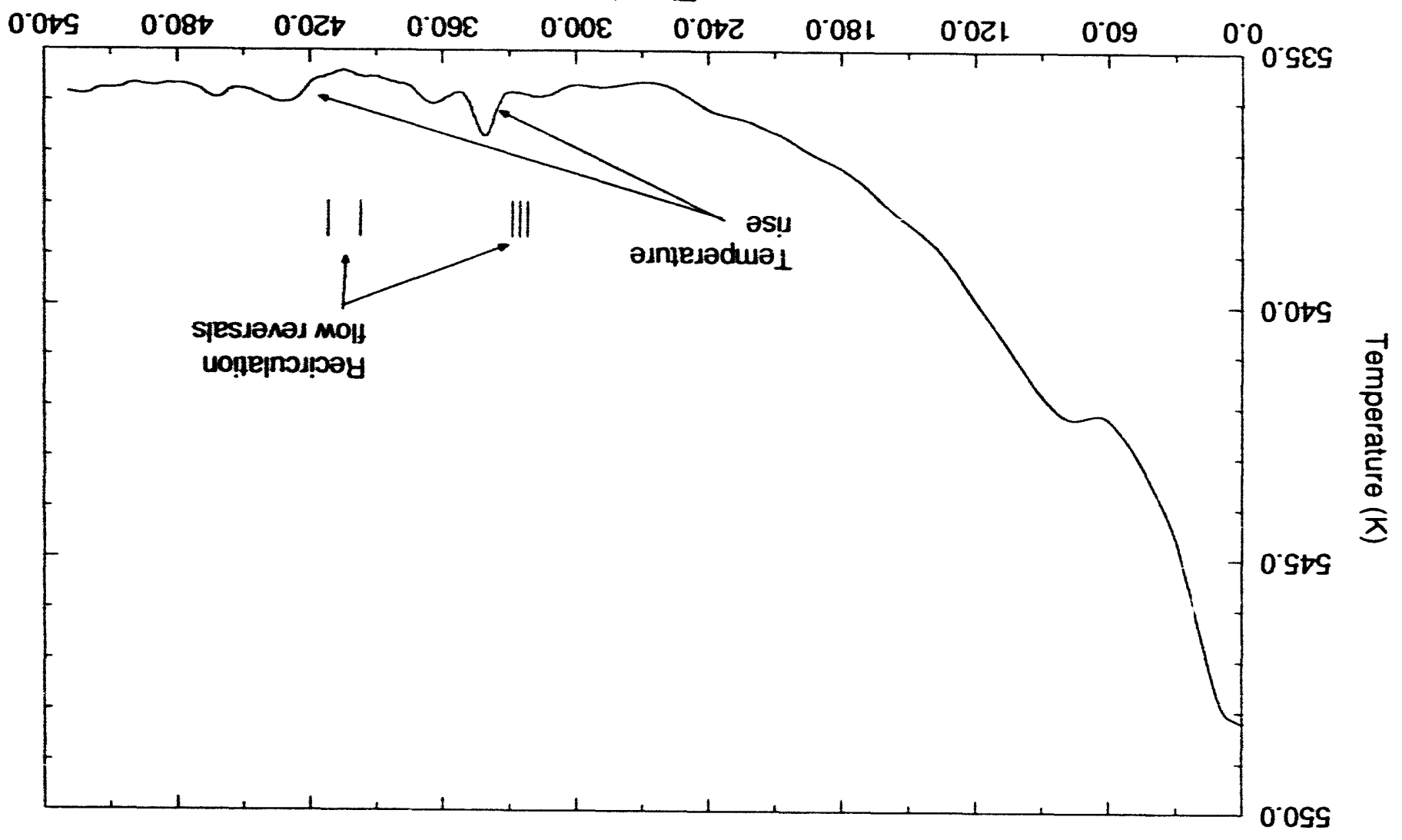




\subsubsection{Feedwater Flow Rate}

The calculated feedwater flow rate is compared to plant process data in Figure 7. The calculated flow rate is a control system output based on the downcomer liquid level error, feedwater-steam flow rate difference, and dome pressure. The calculated value decreases rapidly as the steam flow rate follows the power decline. The feedwater flow rate reaches a near quasi. steady-state prior to responding to the power oscillations, which drive the steam flow and downcomer liquid level oscillations. The steamline backpressure feedback was set at a constant value at 100 seconds to help reduce the oscillation magnitude. This helps stabilize the dome pressure input to the feedwater control system. The feedwater cycle period is longer than that for power and is determined by the control system itself. The magnitudes of the feedwater oscillations are belfeved to be unrealistically large. This would indicate that the control system model for feedwater flow is not representative of the actual plant under these conditions.

The plant process data for feedwater flow responds in a very slow manner to the pump trip as compared to the calculation. The data steady out at a value less than that of the calculation, consistent with the lower than calculated plant power level.

A sensitivity calculation was attempted using the plant data for feedwater flow rate as an input boundary condition instead of the control system output. The additional mass of cold water introduced early (first two minutes) quickly lowered the core inlet temperature, thereby initiating an early and rapidly increasing power oscillation. The power oscillation triggered continuous downcomer recirculation flow reversal, which rendered the calculation meaningless. The large feedwater flow also caused the level of the liquid around the separators to rise well above the separator steam exits.

\subsubsection{Steam Flow Rate}

Figure 8 compares the calculated steamline flow rate with the plant process data. The calculated steami ine flow rate drops sharply with the pump trip and then closely follows the power trend throughout the transient. The plant data follows the plant power trend and reaches a quasi-steady state 
value below the calculated values. The amplitude of the oscillation during the 1 imit cycle exceeds $200 \mathrm{~kg} / \mathrm{s}$. Examination of the STARTREC data indicate the amplitude of oscillations is likely less than $100 \mathrm{~kg} / \mathrm{s}$.

\subsubsection{Steam Dome Pressure}

The calculated steam dome pressure is compared with plant process data in Figure 9. The dome pressure is primarily a function of the power as the steam line exit pressure is determined by the steam line back pressure control system besed on the power. At 100 seconds the exit or back pressure was set constant at its current value in an attempt to reduce the oscillation amplitude of the hydraulic parameters. The plant data is seen to be about $0.05 \mathrm{MPa}$ higher than the calculation throughout the transient. 


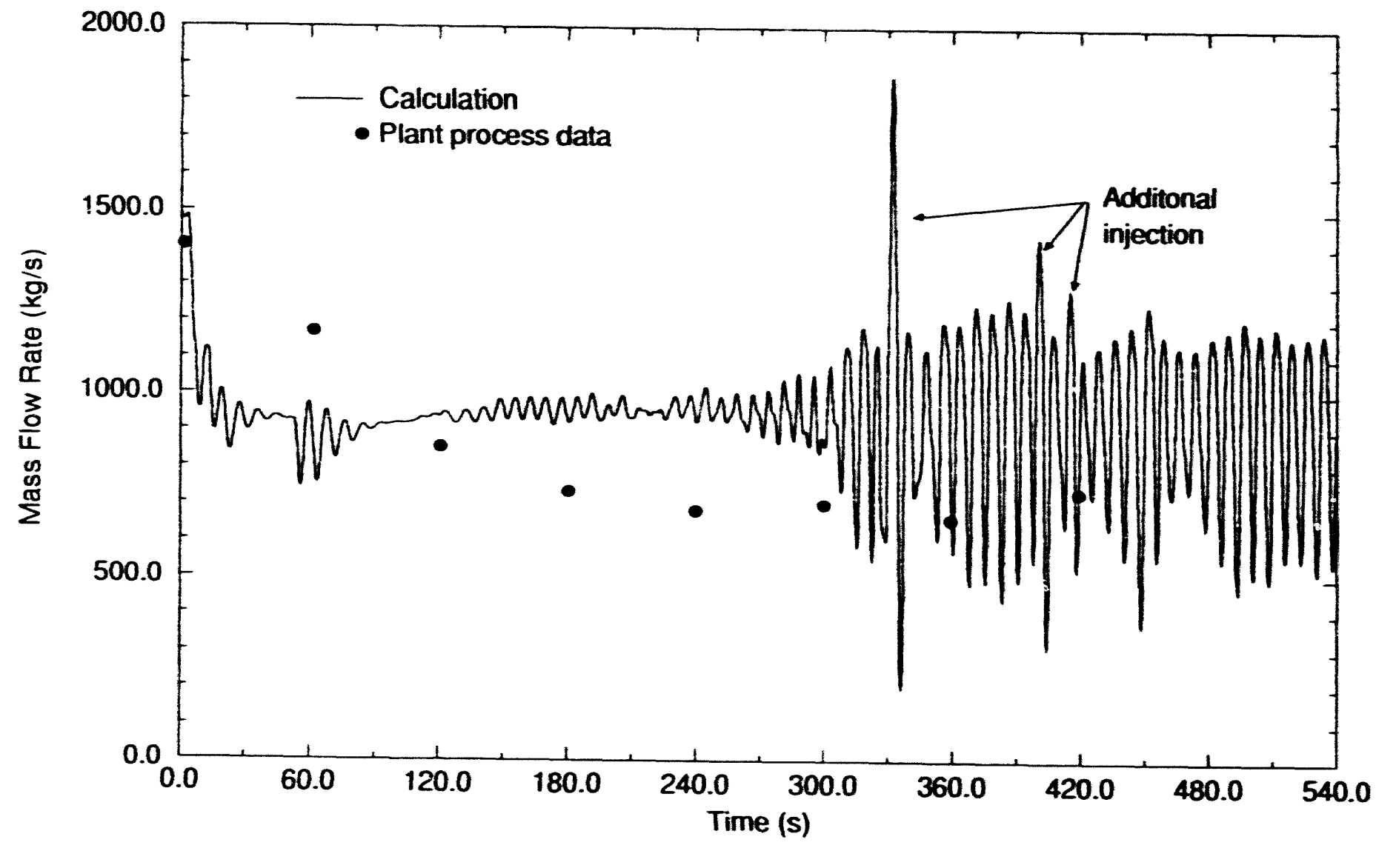

Figure 7. TRAC-BF1 calculated feedwater flow rate compared to plant process data for the LaSalle incident. 


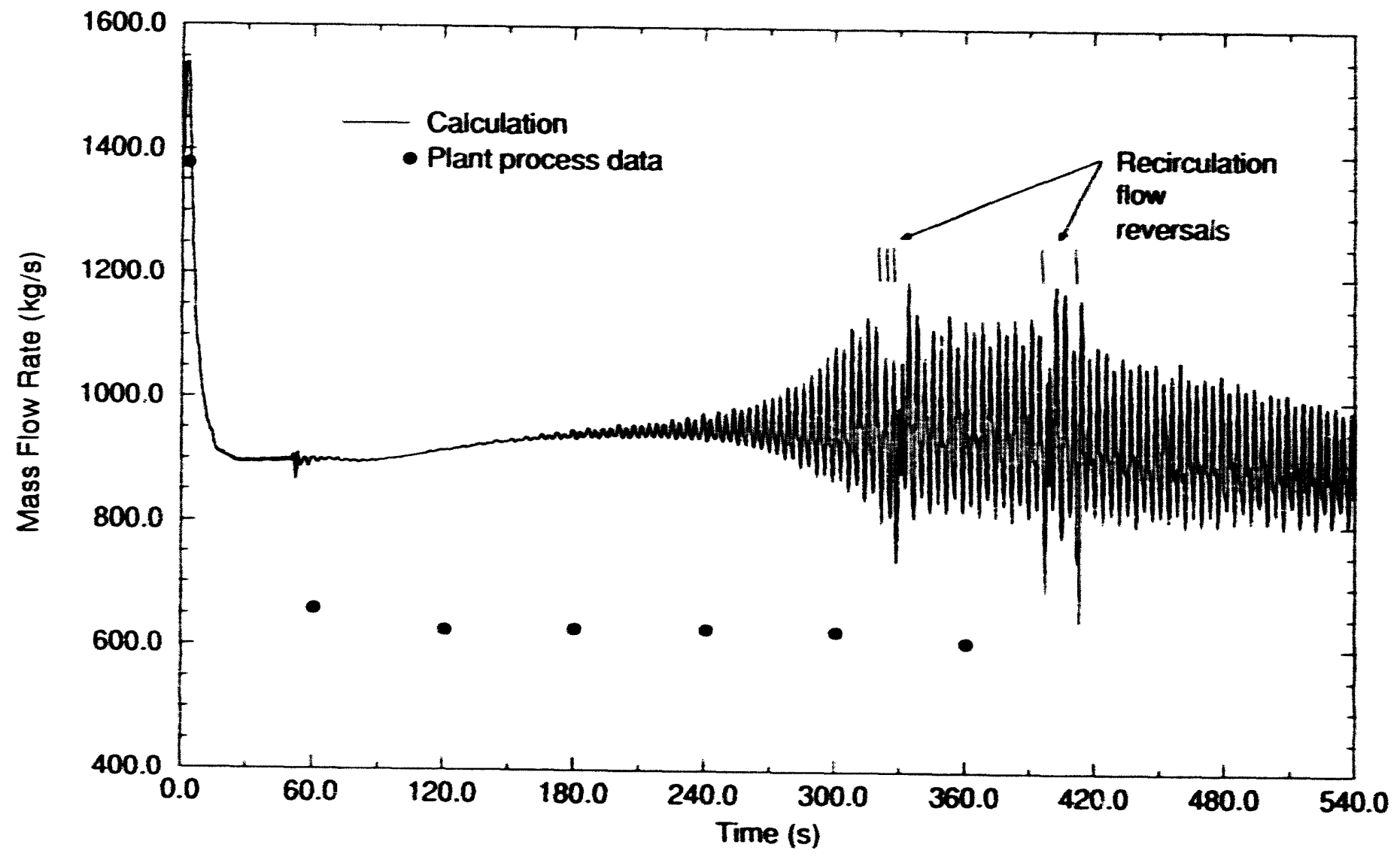

Figure 8. TRAC-BF1 calculated steam line flow rate compared to plant process data for the LaSalle incident. 


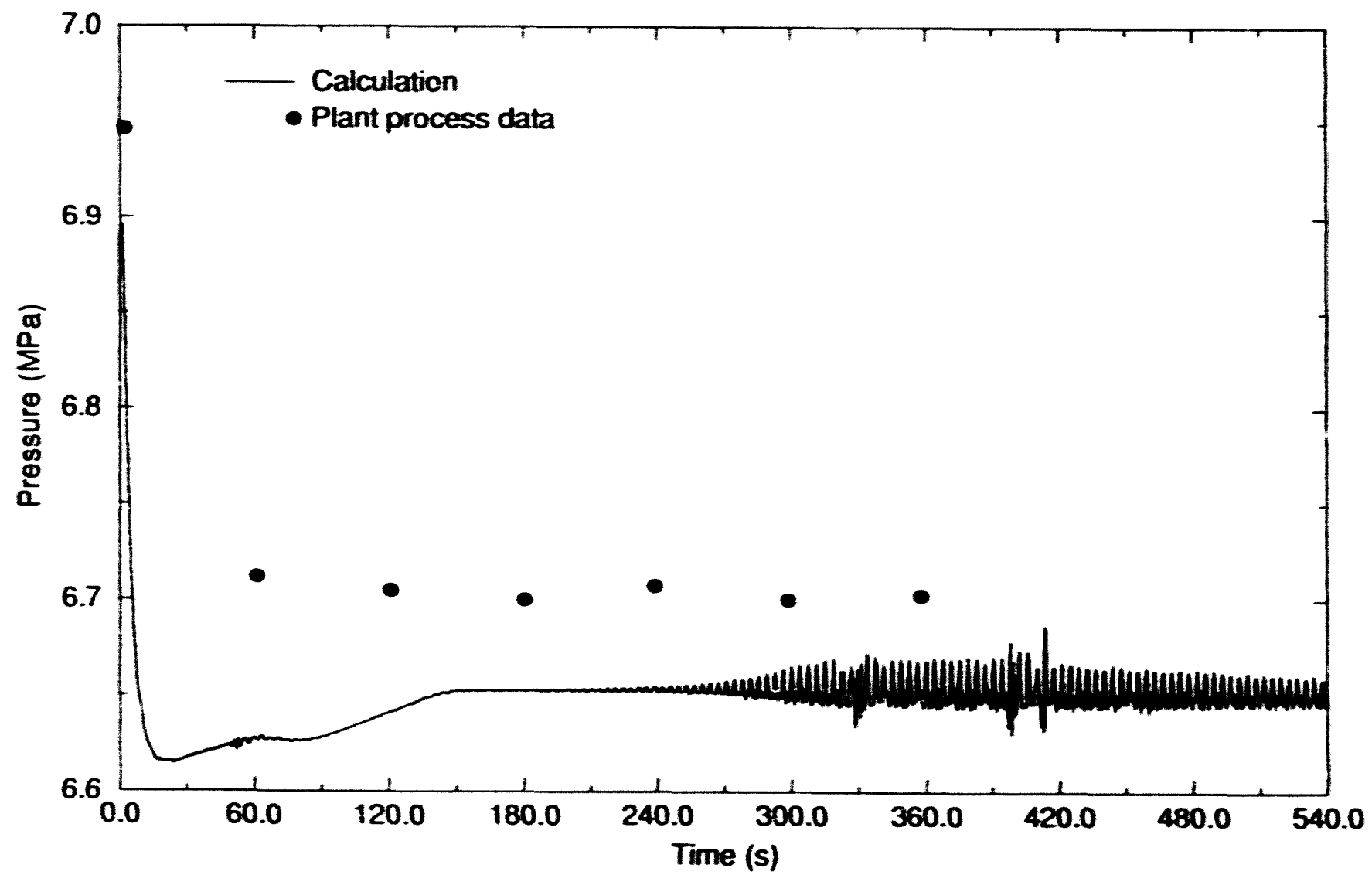

Figure 9. TRAC-BF1 calculated steam dome pressure compared to plant process data for the LaSalle incident. 


\subsubsection{Downcomer Liquid Level}

The calculated downcomer liquid level shown in figure 10 increases sharply with the pump trip but quickly returns to its setpoint and is quite stable unt11 the power oscillation increases in magnitude. The level responds to the oscillating recirculation flow rate, which cycles at the same period as the power, and the feedwater flow rate, which has a longer period. As Indicated by the STARTREC data, the oscillation amplitude of the plant liquid level is no more than about $0.1 \mathrm{~m}$.

The recirculation flow instability eventually increases causing the downcomer return flow to reverse or nearly reverse, and the downcomer liquid level almost drops into the next lower axial level. The recirculation flow then returns to the downcomer, pumping addittonal higher temperature liquid to the core inlet. The downcomer level decrease causes increased feedwater to be injected by the feedwater control system which then has a cooling effect on the core inlet temperature.

The initial instabilities are triggered during the limit cycle development and at the high power sustained by the quasi-steady 1 imit cycle. Following the second oscillation set the system recirculation ratio increases with a consequent slight reduction in average power.

\subsection{Core Reactivity Behavior}

Changes in the core reactivity during the transient consequently change the power. The total reactivity is the sum of reactivity components that respond to changes in core void fraction, fuel temperature and moderator temperature. These changes are spatially distributed throughout the core but are lumped into volume-weighted averages and assumed to be represented by point kinetics reactivity coefficients. The individual reactivity components are positive or negative but must sum to zero at steady state. As the reactivity calculation was initiated when the transient was initiated, the time zero values shown for the components are not precisely correct. The total reactivity and components are described below. 


\subsubsection{Total Reactivity}

The total reactivity is shown in Figure 11. After the initial perturbation the total reactivity recovers to near steady-state conditions. With the start of channel flow oscillation, the reactivity oscillates with a negative average. A quast-steady limit cycle exists following the first downcomer osclllations. After the second downcomer osclllation set, the average reactivity increases approaching zero. 


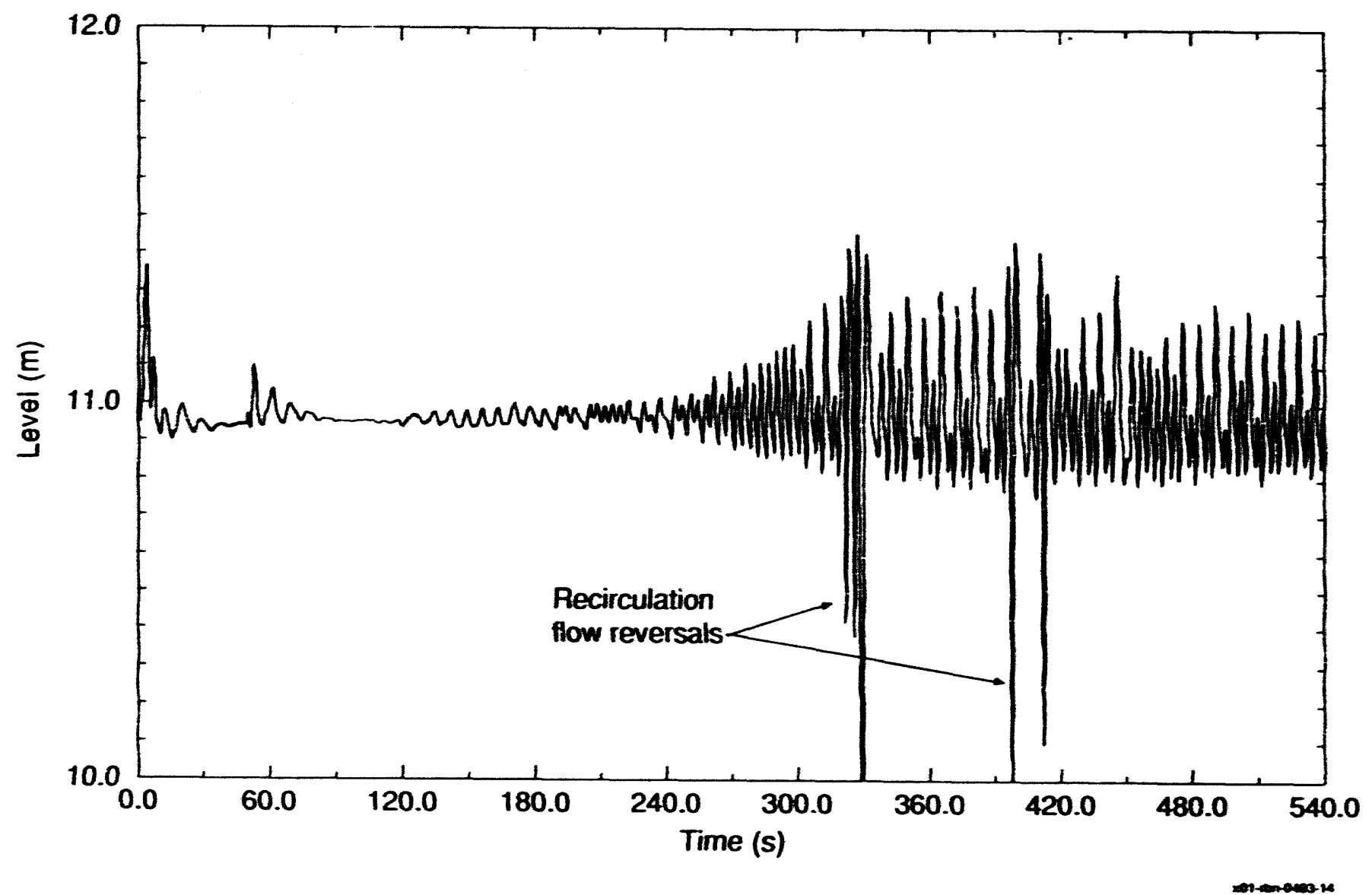

Figure 10. TRAC-BF1 calculated downcomer liquid level for the LaSalle incident. 


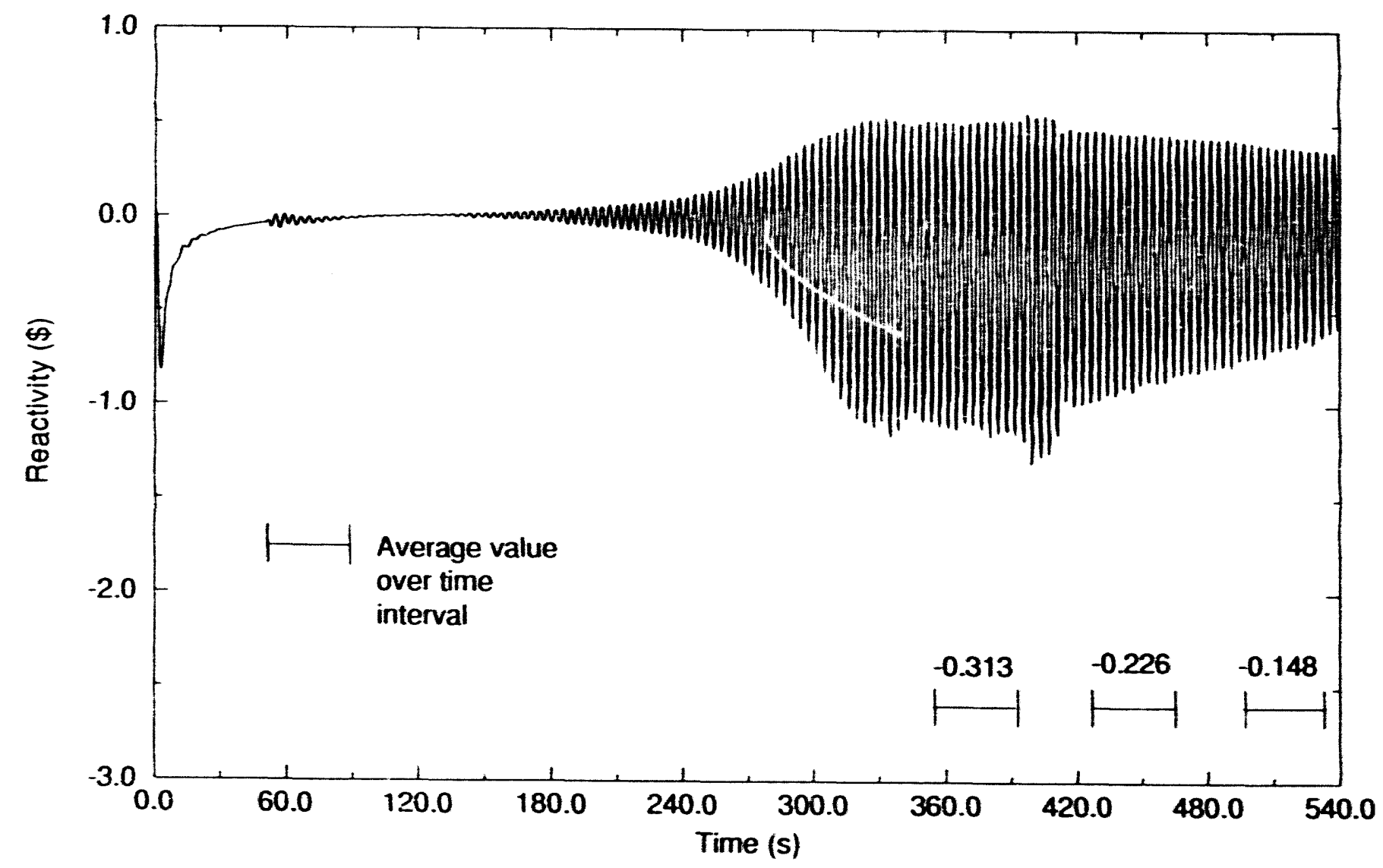

Figure 11. TRAC-BF1 calculated total reactivity for the LaSalle incident. 


\subsubsection{Core Average Void Reactivity}

This reactivity component responds to the changes in core void. The calculated core average void fraction is shown in Figure 12. The core average void is the largest factor affecting reactivity and power. The void increases sharply with the initial decrease in core flow and decreases to a quasi-steady value slightly higher than the initial value. With the onset of the channel oscillations, the peak void values increase sharply even though the average void increases only slightly. The void oscillations are approximately 180 degrees out-of-phase with the power oscillations. After the second downcomer oscillation set, ihe peak void values decrease sharply with the average void decreasing slightly, approaching a new steady-state value.

The calculated core average void reactivity is shown in Figure 13. The increase in peak negative values following the second downcomer oscillation corresponds to the decrease in peak void values.

\subsubsection{Average Fuel Temperature Reactivity}

The calculated average fuel temperature is shown in Figure 14 . The average fuel temperature responds instantaneously to the power and more slowly to the average channel flow rate. After peaking between the second downcomer oscillation set, the fuel temperature decreases to a new average steady-state value.

The calculated fuel temperature reactivity is shown in Figure 15. The minimum values correspond to the peak fuel temperatures previously shown in Figure 14 between the second downcomer oscillation set. At the time the calculation is terminated, the value appears to be converging toward an average positive value near 0.3 , which along with the moderator temperature reactivity component roughly equals the inverse of the average void reactivity component.

\subsubsection{Average Moderator Temperature Reactivity}

The calculated average moderator temperature is shown in Figure 16. The average moderator temperature is the average for the fluid contained in the 
fuel channels. It excludes the bypass region fluid. It reaches a near steady-state value at 250 seconds. The downcomer oscillations cause a slight perturbation in the values. Since the recirculation ratio is increasing slightly as the transient proceeds the trend for the moderator temperature at calculation termination is also slightly increasing.

The calculated moderator reactivity is shown in Figure 17. This reactivity component value increases with the decrease in average moderator temperature. This reactivity component is the least important of the three as it has the smallest value.

\subsection{Fuel Channel Behavior}

The following sections describe the behavior of the channel inlet and exit mass flow rates, the inlet single-phase and exit two-phase pressure drops, and leakage during the quasi-steady limit cycle period of the transient. 


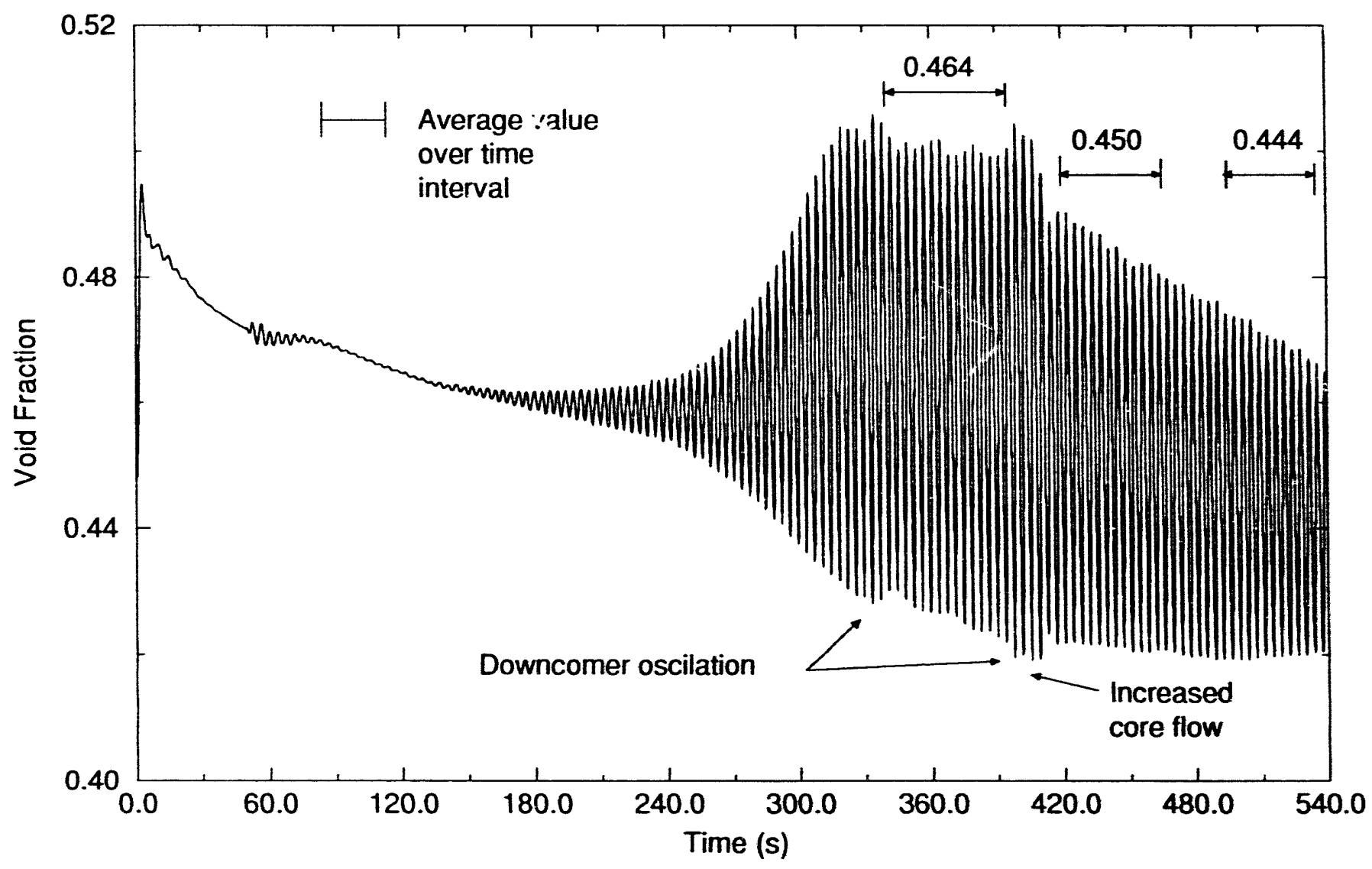

Figure 12. TRAC-BF1 calculated core average void for the LaSalle incident. 


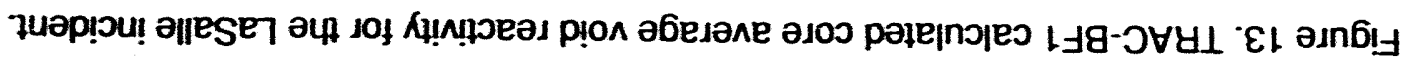
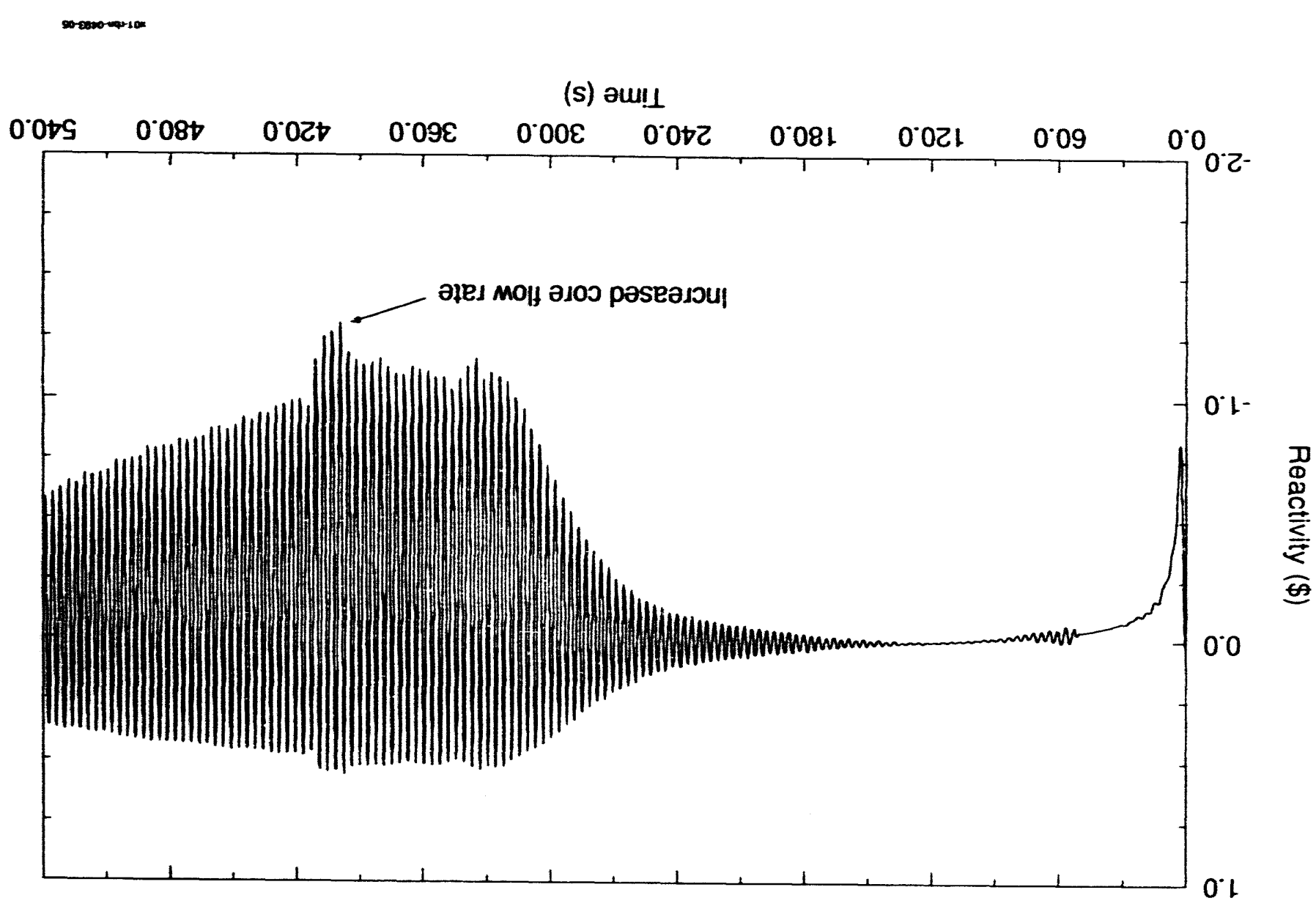


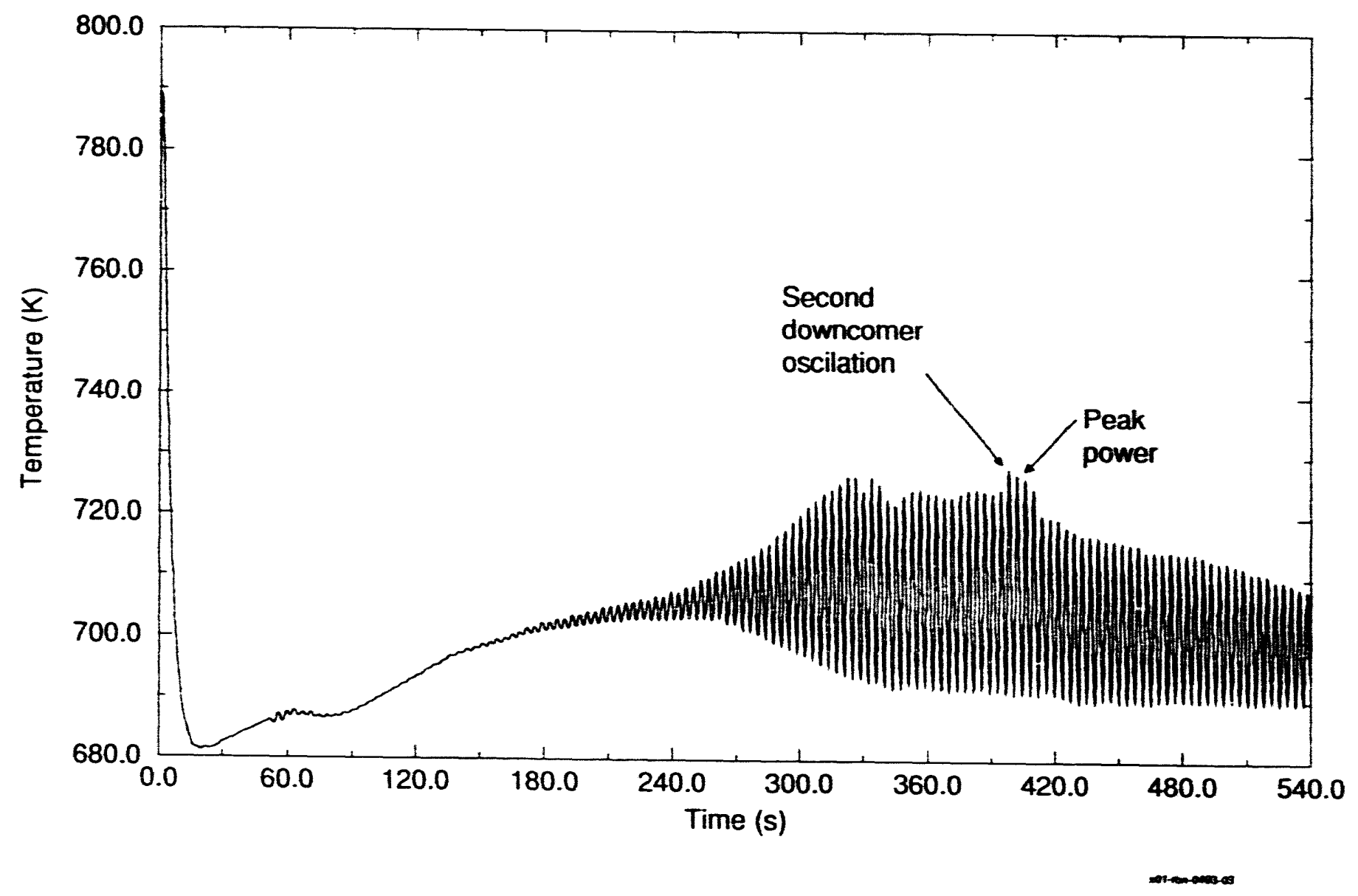

Figure 14. TRAC-BF1 calculated average fuel temperature for the LaSalle incident. 


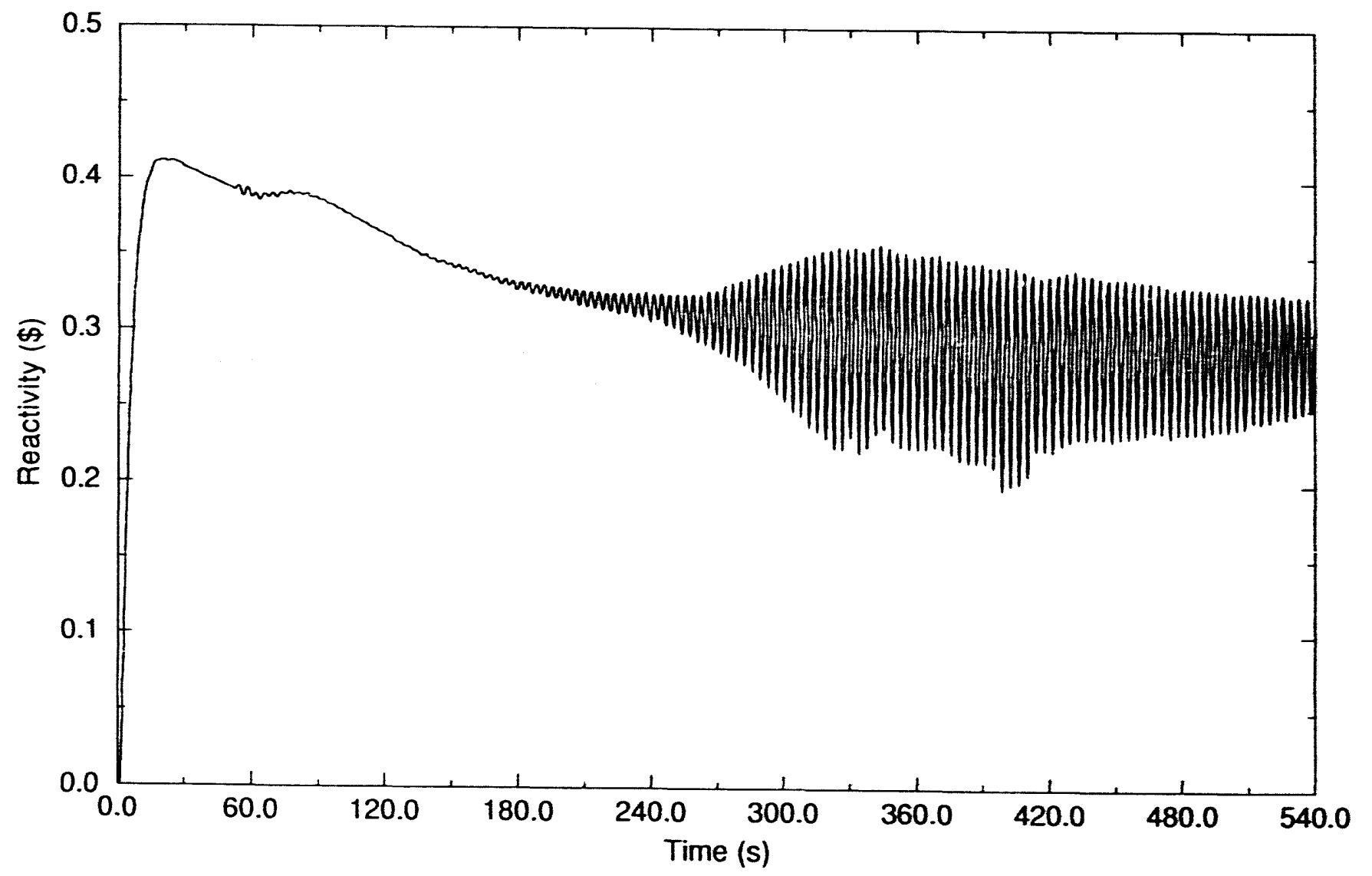

Figure 15. TRAC-BF1 calculated fuel temperature reactivity for the LaSalle incident. 


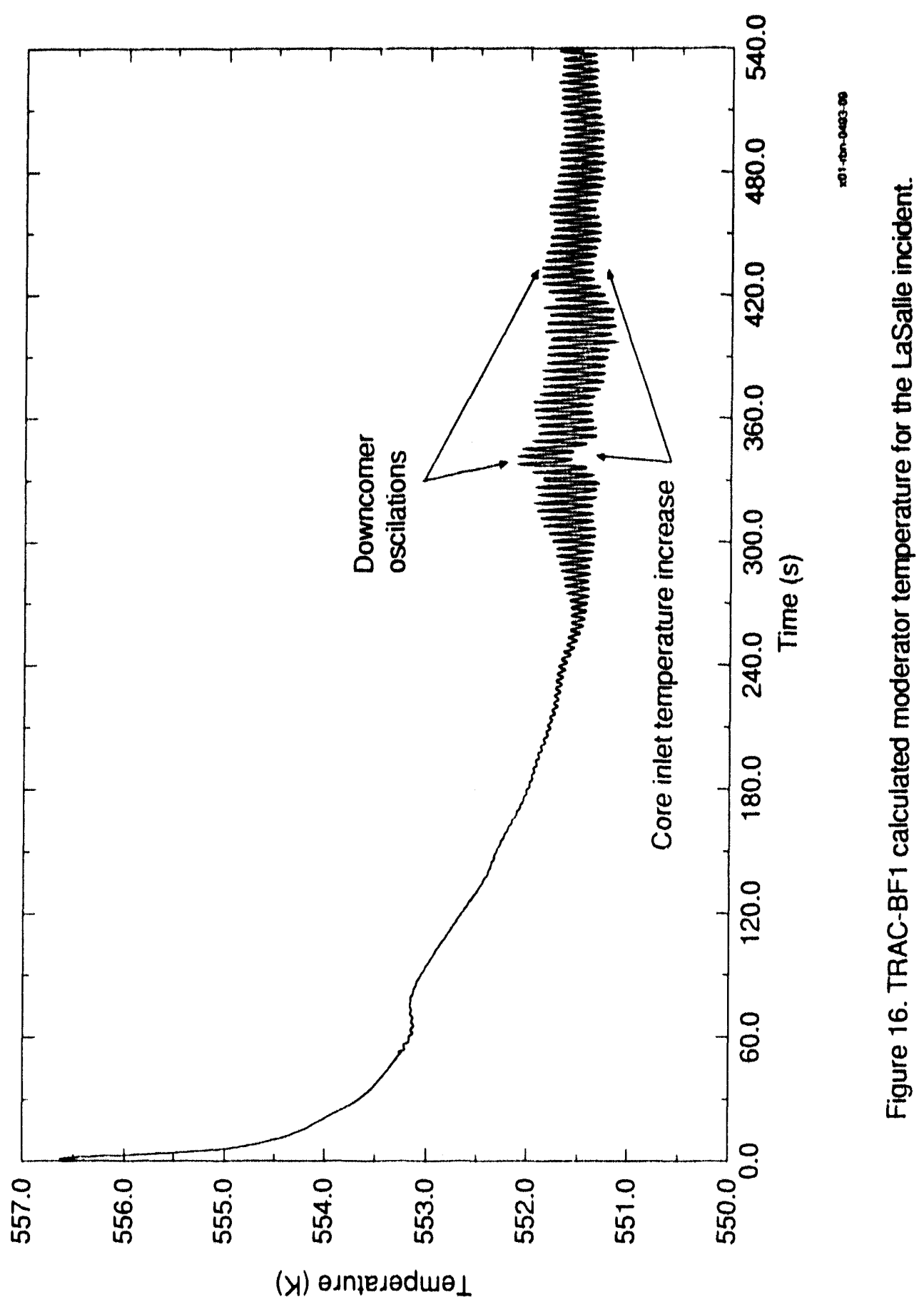




\subsubsection{Mass Flow Rates}

Figure 18 shows the calculated channel inlet and exit flow rates for a typical high-powered channel located in the center ring. The fllustration is for the time period between the downcomer oscillations when a quasi-steady limit cycle exists. The inlet and exit flow rates oscillate in nearly opposite phase, characteristic of two-phase flow instability. The exit flow peak slightly precedes the inlet flow minimum. The average exit flow rate is larger than the inlet as the average channel leakage is into the channel from the core bypass region.

The behavior of the low power channel representing the core periphery fuel bundles is not the same. The phase shift between the inlet and exit flow rates is only slight. This is because the high-powered channels drive the flow oscillation.

\subsubsection{Single and Two-Phase Pressure Drops}

Figure 19 shows the pressure drops at the channel inlet and exit for the same channel as shown in Figure 18. As expected, the pressure drops are essentially 180 degrees out-of-phase. The illustration shows the single-phase pressure drop across the first three channel flow junctions and the two-phase pressure drop across the last seven junctions at the channel exit. If one includes the two-phase pressure drop through the separator with that of the channel exit, the two-phase value considerably exceeds that of the singlephase. For the peripheral channel the two-phase pressure drop is smaller in comparison to the single-phase pressure drop than shown for the high power channels.

\subsubsection{Channel Leakage Flow Rate}

Figure 20 shows the calculated channel leakage flow rate. As illustrated, the leakage flow rate is initially out of the channel and into the core bypass region. The leakage flow reverses during the flow coastdown following pump trip. The maximum leakage values (near zero) occur during the power oscillations coincident with the power peaks. After flow reversal, a considerable portion of the core bypass flow is diverted into the channels. 


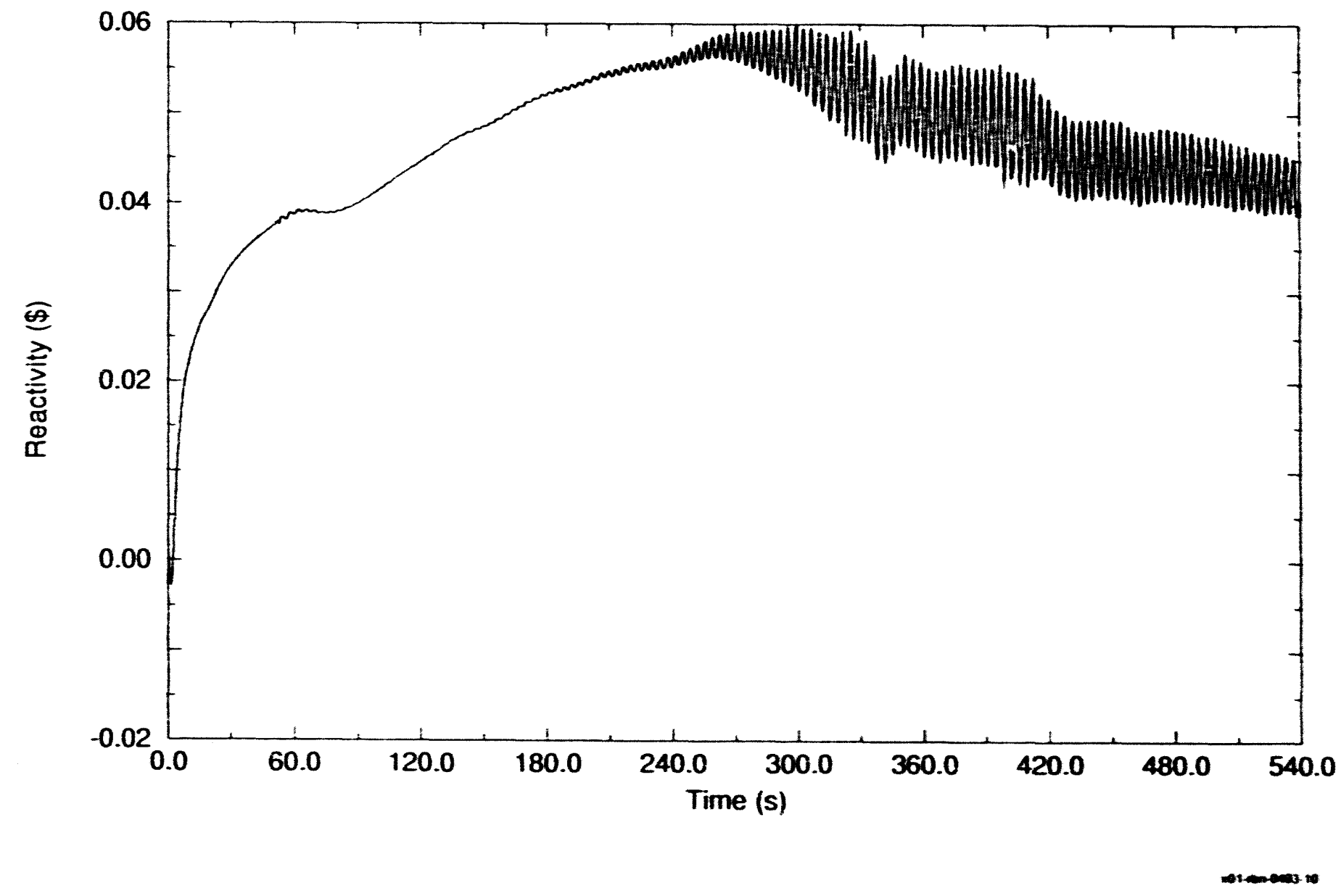

Figure 17. TRAC-BF1 calculated average moderator temperature reactivity for the LaSalle incident. 


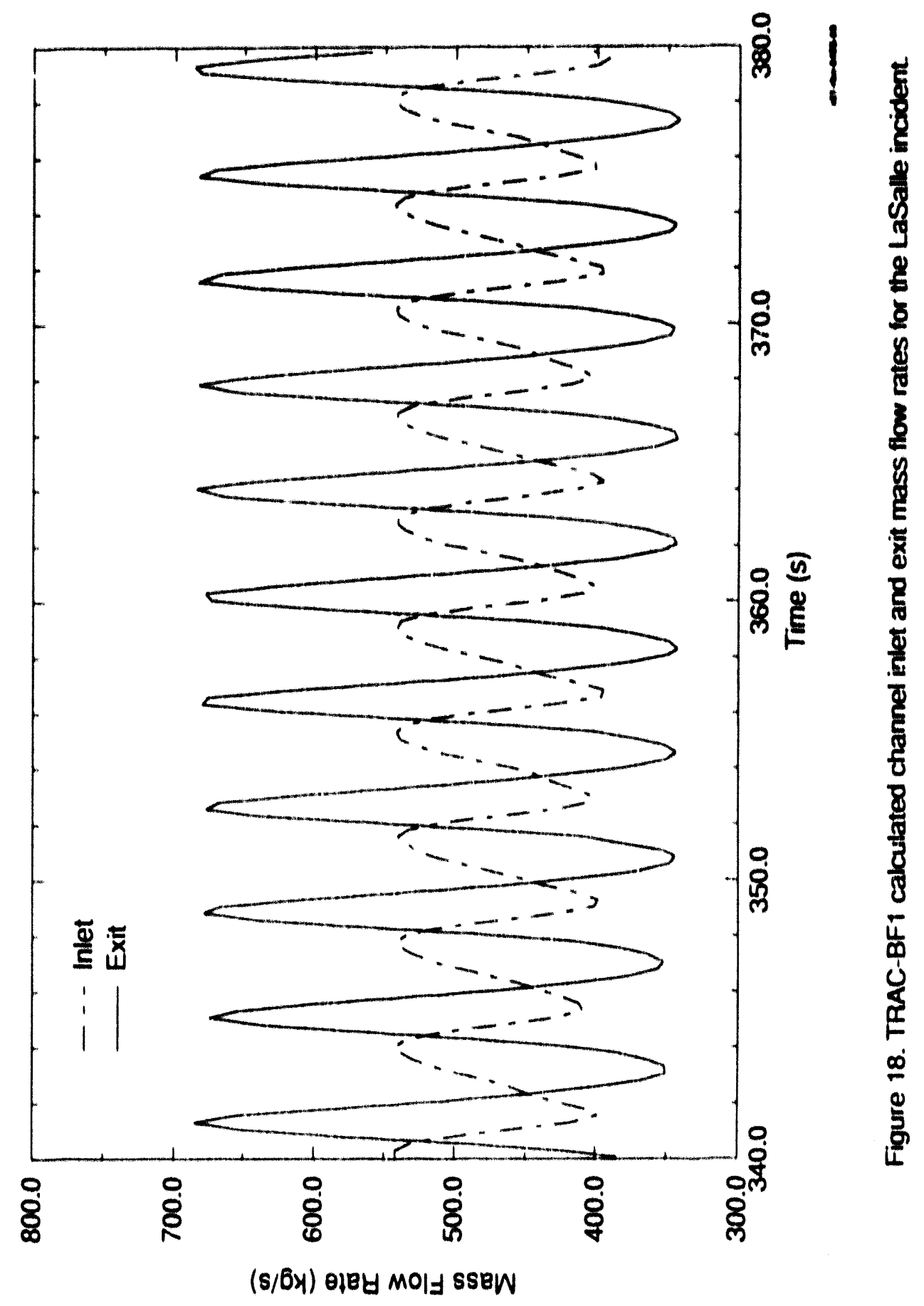




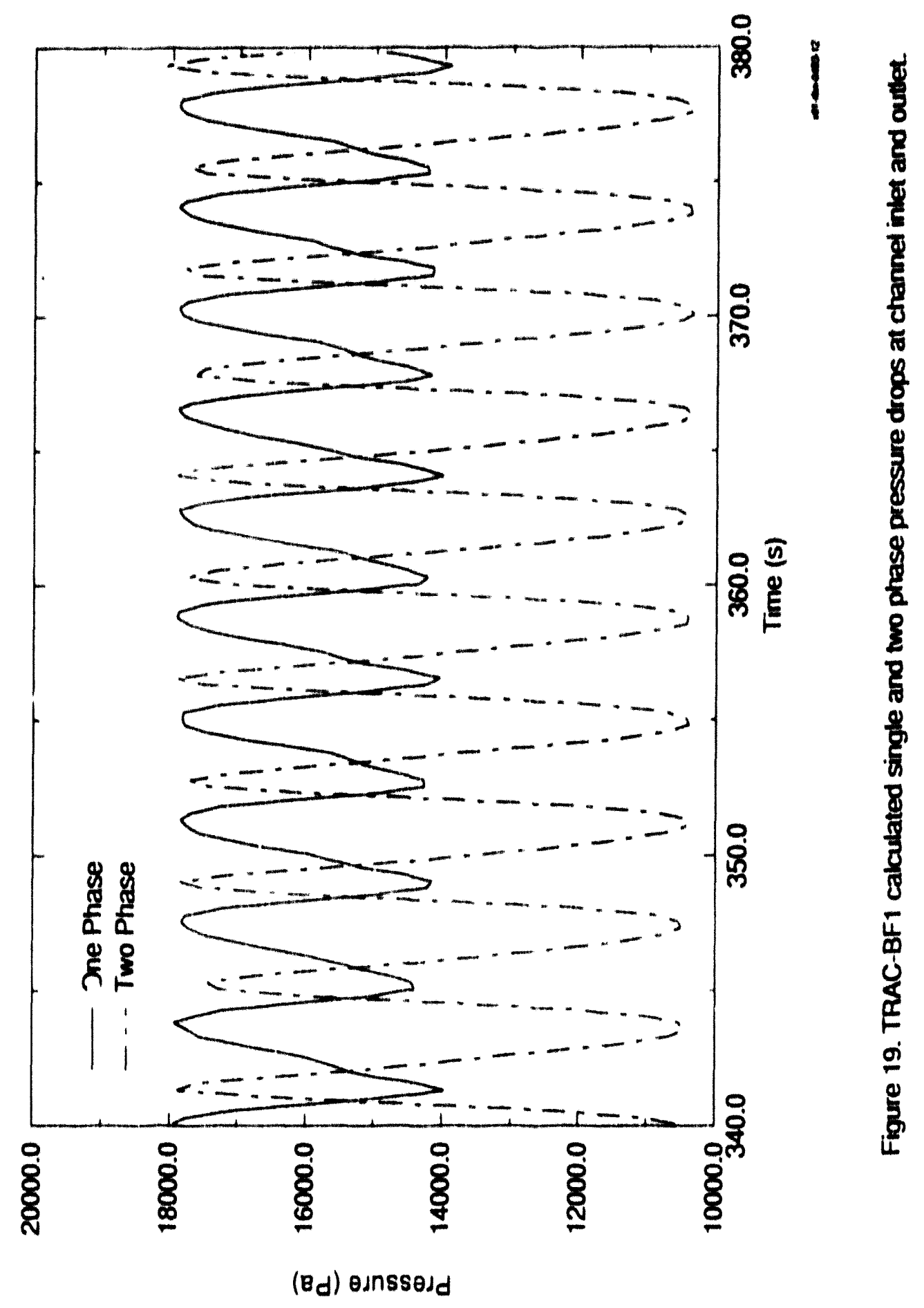




\subsection{InstaBILITY}

Preliminary results not presented exhibited considerably more downcomer flow instability than the results shown. Removal of the liquid level model function in level 9 where the normal liquid level is to be found dramatically improved the behavior. At this time an unexplained secondary recirculation pattern within the fluid between the plenum and steam dryers was al so noted. El iminating the liquid level function also changed the steady-state and transient interior llauid levels and the observed secondary recirculation pattern.

The downcomer oscillations that remain are belleved to be an artificial phenomenon induced by a numerical instability resulting from the steam separators. This is based on several observations. The first being the unstable behavior of the separators when the mechanistic code option was selected during preliminary calculations. Results could not be obtained with that option. The second being that during the transient as the core flow rate decreased following pump trip, the separator flow rates became progressively more notsy, and were very noisy during natural circulation before the power began to oscillate. Also after this work, during independent calculations for another plant with a similar model to that reported here, it was found that by eliminating the separator located in the periphery ring, erratic behavior was eliminated permitting reasonable results. 


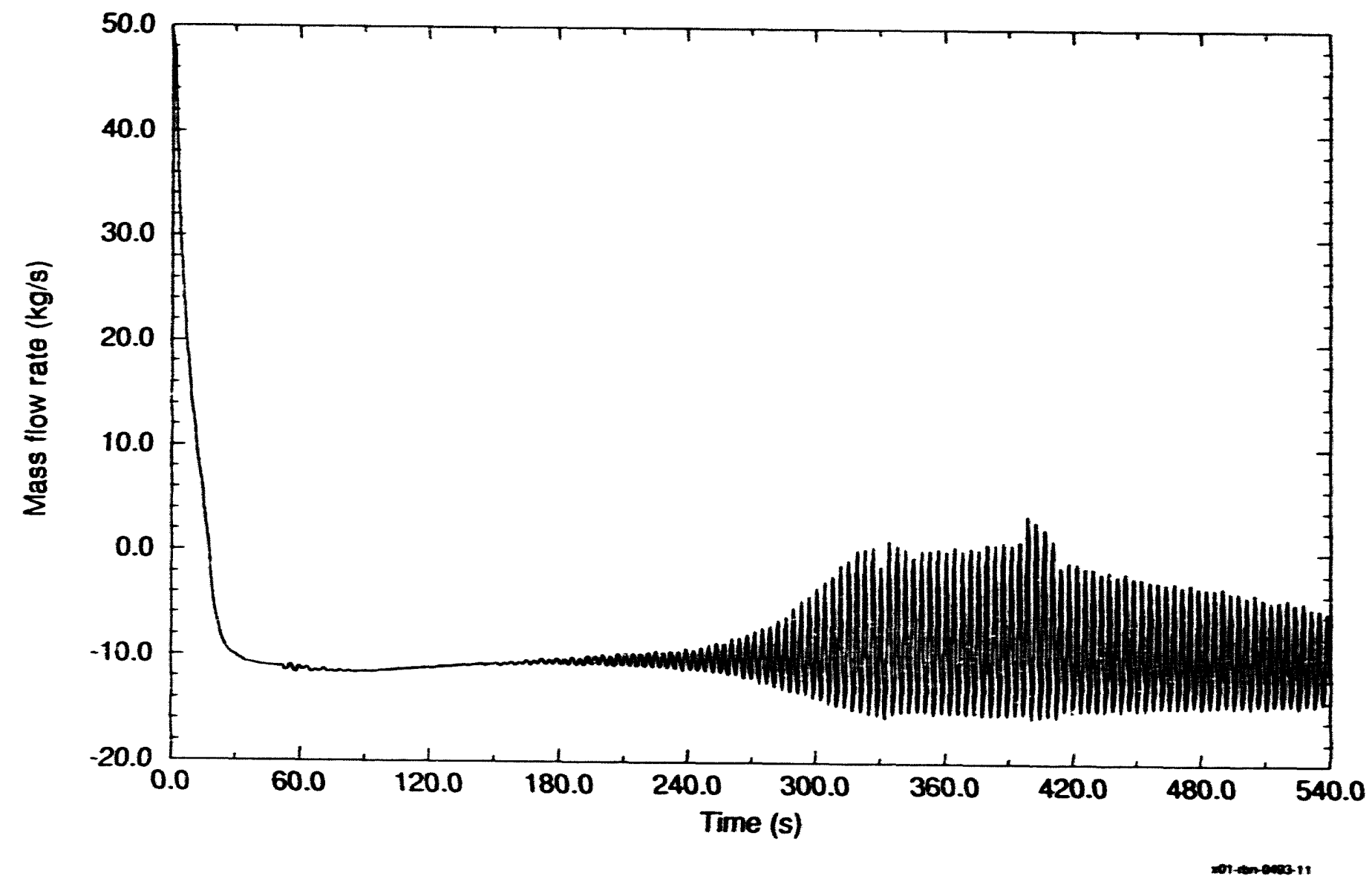

Figure 20. TRAC-BF1 calculated channel leakage flow rate for the LaSalle incident. 


\section{CONCLUSIONS}

A simulation of the LaSalle instability event has been performed using the TRAC-BFI computer code. Analysis of the simulation and comparison to limited plant data results in the following conclusions:

1. The TRAC-BFI model does predict the onset on instability and the development of limit cycle oscillations. However, using either the GE-supplied or BNL-supplied vold reactivity coefficient results in an earlier onset of instability and more rapid growth in power oscillations than occurred in the plant.

2. The period of the oscillations calculated by TRAC-BFI is 3.8 seconds whereas the measured period in the plant was 2.3 seconds. This difference could be attributed to several factors, including the use of point kinetics and the lack of realistic interaction with the steam flow controller and feedwater controller. It is known that longer period osctillations result in higher power peaks.

3. The sensitivity of the point of onset and magnitude of the power oscillations to small changes in the void reactivity coefficient is dramatic. The BNL-supplied coefficient produced results closer to observed plant behavior.

4. The TRAC-BFI calculation exhibits a trend of increasing recirculation ratio after the largest power peaks were obtained. This increases feedwater heating in the downcomer, thereby reducing subcooling at the core inlet. This "self-correcting" behavior is considered plausible. 


\section{REFERENCES}

1. W. W. Weaver, et a1., "TRAC-BF1 Manual: Extensions to TRAC-BD1/MOD1," Idaho National Engineering Laboratory, Idaho National Engineering Laboratory, NUREG/CR-4391, EGG-2417, August 1986.

2. Los Alamos National Laboratory Code Safety Development Group, "TRAC-PD2, An Advanced Best Estimate Computer Program for Pressurized Water Reactor Loss-of-Coolant Accident Analysis," LA-8709-MS. NUREG/CR-2054, Apri1 1981 .

3. J. Spore, et a1., "TRAC-BD1: An Advanced Best Estimate Computer Program for Boiling Water Reactor Loss-of-Coolant Analysis, "Idaho National Engineering Laboratory, NUREG/CR-2178, October 1981.

4. D. D. Taylor, et a1., "TRAC-BD1/MOD1: An Advanced Best Estimate Computer Program for Boiling Water Reactor Transient Analysis," Idaho National Engineering Laboratory, NUREG/CR-3633, EGG-2294, Apri1 1984.

5. J. C. Shaug 1tr to S. Z. Rouhani, April 12, 1990.

6. R. A. Roehl 1tr to Gary E. Wilson, Agreement Concerning the Handling of Proprietary Information, March 10, 1989.

7. J. C. Shaug 1tr to J. R. Larson, December 19, 1989. 

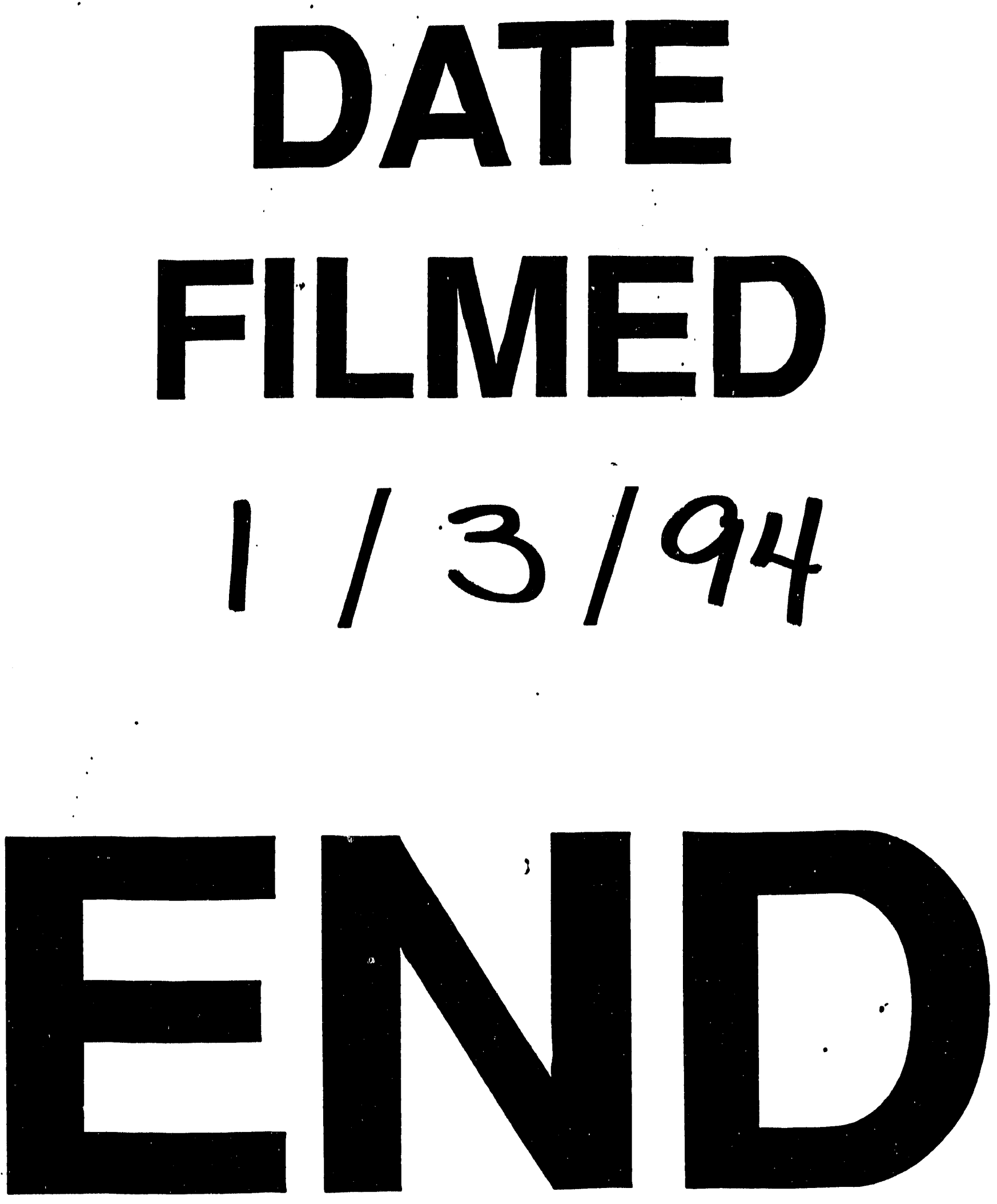
